\title{
Structure-Based Discovery of a Novel Small-Molecule Inhibitor of Methicillin-Resistant S. aureus
}

\author{
Jie Liu, ${ }^{1}$ Lina Kozhaya, ${ }^{2}$ Victor J. Torres, ${ }^{3}$ Derya Unutmaz, ${ }^{2}$ and Min Lu ${ }^{1, *}$ \\ ${ }^{1}$ Public Health Research Institute \\ Department of Microbiology, Biochemistry and Molecular Genetics \\ Rutgers Biomedical and Health Sciences \\ Newark, New Jersey 07103 \\ ${ }^{2}$ The Jackson Laboratory for Genomic Medicine \\ Farmington, CT 06032 \\ ${ }^{3}$ Department of Microbiology \\ New York University School of Medicine \\ New York, NY 10016
}

*Correspondence: lum1@njms.rutgers.edu 


\section{Summary}

The rapid emergence and dissemination of methicillin-resistant Staphylococcus aureus (MRSA) strains represents a major threat to public health. MRSA elaborates an arsenal of secreted hostdamaging virulence factors to mediate pathogenicity and blunt immune defense. PantonValentine leukocidin (PVL) and $\alpha$-toxin are pore-forming cytotoxins of recognized importance in the development of invasive MRSA infection and are thus potential targets for antivirulence therapy. We report the X-ray crystal structures of PVL and $\alpha$-toxin in their soluble, monomeric and oligomeric, membrane-inserted pore states, in complex with n-tetradecylphosphocholine $\left(\mathrm{C}_{14} \mathrm{PC}\right)$. The structures reveal two evolutionarily conserved phosphatidylcholine binding mechanisms and their roles in modulating host cell attachment, oligomer assembly and membrane perforation. Moreover, we demonstrate that the soluble $\mathrm{C}_{14} \mathrm{PC}$ compound protects primary human immune cells in vitro against cytolysis by PVL and $\alpha$-toxin and hence may serve as the basis for the development of novel antivirulence agents to combat MRSA. 


\section{Introduction}

Infection with Staphylococcus aureus can cause severe and devastating illness and is one of the leading causes of death by any infectious agent in the United States (Klevens et al., 2007; Lowy, 1998). S. aureus is notorious for its ability to acquire genetic determinants of antibiotic resistance and virulence that enhance fitness and pathogenicity (Chambers and Deleo, 2009; Otto, 2010). Methicillin-resistant S. aureus (MRSA) now accounts for $>60 \%$ of S. aureus isolates in US intensive care units, severely restricting antibiotic treatment options (Klevens et al., 2007). MRSA also spreads rapidly among healthy individuals in the community, causing predominantly skin and soft tissue infections and a number of unusually severe clinical syndromes, including necrotizing pneumonia and septic shock (Klevens et al., 2007). Disturbingly, MRSA can live in the biofilm state (Jones et al., 2001; Otto, 2008), and it has long been recognized that biofilms increase resistance to antimicrobial agents and the host immune response (Bowler, 2018). Both vancomycin and daptomycin are key last-line agents for treatment of invasive MRSA infections (Liu et al., 2011). Alarmingly, MRSA strains that are even resistant to vancomycin have emerged recently (Courvalin, 2006; Gardete and Tomasz, 2014). For these reasons, the World Health Organization identifies MRSA as one of six 'high priority' pathogens that pose an enormous threat to public health (Willyard, 2017). Therefore, new therapeutics with novel mechanisms of action and that interfere with new targets are desperately needed to combat this high threat pathogen.

USA300 is the most prevalent strain of MRSA in the US and represents a growing threat in both the community and healthcare settings (Diekema et al., 2014). Its heightened incidence and severity have been related to the production of a cocktail of cytolytic pore-forming exotoxins mediating virulence and impairing host immune defenses (Diep et al., 2006; Otto, 2010). The pharmacological targeting of these cytotoxins may be highly effective and lead to a lower selective pressure for resistance than traditional antibiotics. Bipartite leukocidins and single-component $\alpha$ toxin, secreted by S. aureus as water-soluble, monomeric polypeptides, constitute the $\alpha$-hemolysin subfamily of $\beta$-barrel pore-forming toxins (Gouaux et al., 1997). Five different leukocidins have been described, including Panton-Valentine leukocidin (PVL), leukocidin ED (LukED), two $\gamma$ hemolysins (HlgAB and HlgCB) and leukocidin AB (LukAB; also known as LukGH), each of which consists of two distinct polypeptides referred to as the $\mathrm{S}$ and $\mathrm{F}$ subunits (for a review see Alonzo and Torres, 2014). Their cellular tropism and species specificity are determined by the S 
subunits LukS-PV, LukE, HlgA, HlgC and LukA (Alonzo et al., 2013; Gauduchon et al., 2001; Spaan et al., 2017). The $\mathrm{S}$ and F subunits and $\alpha$-toxin share a unique modular structure consisting of the amino latch and prestem regions and the $\beta$-sandwich and rim domains (see Figure 1A) (Guillet et al., 2004; Nocadello et al., 2016; Olson et al., 1999; Pedelacq et al., 1999; Sugawara et al., 2015). The X-ray crystal structures of the membrane-inserted pore oligomer forms of $\alpha$ toxin, $\mathrm{HlgAB}$ and $\mathrm{LukGH}$ and of the membrane surface-bound prepore heterooctamer forms of HlgAB and HlgCB have been determined (Badarau et al., 2015; Song et al., 1996; Yamashita et al., 2014; Yamashita et al., 2011). These structures, and supporting biochemical and genetic data (Sugawara et al., 2015; Valeva et al., 1997; Walker and Bayley, 1995; Yokota and Kamio, 2000), suggest that members of this subfamily share a common mechanism of cytolytic action (for reviews see Dal Peraro and van der Goot, 2016; Kawate and Gouaux, 2003). The cytolytic process begins with the binding of soluble toxin monomers to a cell surface receptor (Berube and Bubeck Wardenburg, 2013; Spaan et al., 2017). The membrane-bound monomers then associate to form a nonlytic, oligomeric prepore. Finally, the translocation of the prestem regions across the membrane results in the bilayer-spanning $\beta$-barrel pore structure and consequent membrane permeabilization and cell lysis.

MRSA strains that harbor the phage-encoded PVL have been linked to highly virulent and severe community-acquired skin infections (Lina et al., 1999), as well as life-threatening disease (Gillet et al., 2002). The role of PVL production in the pathogenesis of MRSA was demonstrated in a rabbit model of necrotizing pneumonia (Diep et al., 2010). PVL induces leukocyte destruction and tissue necrosis through interaction with the complement receptors C5aR and C5L2 (Loffler et al., 2010; Spaan et al., 2013; Ward and Turner, 1980; Woodin, 1960). PVL, in conjunction with HlgAB, contributes to MRSA biofilm-mediated killing of neutrophils (Bhattacharya et al., 2018). On the other hand, the chromosomally encoded $\alpha$-toxin lyses epithelial and endothelial cells, lymphocytes and monocytes by targeting its receptor, the metalloprotease ADAM10 (Berube and Bubeck Wardenburg, 2013; Wilke and Bubeck Wardenburg, 2010). The elevated expression of $\alpha$ toxin in the USA300 clone and in historic human epidemic strains correlates with increased pathogenicity in mouse models of pneumonia and sepsis (Bubeck Wardenburg and Schneewind, 2008; DeLeo et al., 2011). $\alpha$-Toxin also plays a role in biofilm formation by clinical MRSA isolates (Anderson et al., 2018). Moreover, LukED relies on the chemokine receptor CCR5 to kill $\mathrm{T}$ lymphocytes, macrophages and dendritic cells, as well as CXCR1 and CXCR2 to kill leukocytes 
(Alonzo et al., 2013; Reyes-Robles et al., 2013). Inhibition of the interaction between LukED and CCR5 has been shown to block cytotoxicity and attenuate S. aureus infection in mice (Alonzo et al., 2013). Together, these cytotoxins can collaborate to modulate phagocytic cell functions via their specific receptors and contribute to MRSA immune evasion and disease pathogenesis. As such, the discovery and development of new antivirulence agents that protect against the combined cytopathic effects of this subfamily of pore-forming toxins are the subject of intense pharmaceutical efforts.

There is considerable evidence pointing to the role of phosphatidylcholine (PC) in the mechanism of pore formation by these toxins. PC is an absolute requirement for pore formation by $\alpha$-toxin, $\mathrm{H} \lg \mathrm{AB}$ and $\mathrm{H} \lg \mathrm{CB}$ and has been shown to inhibit their cytolytic effects (Ferreras et al., 1998; Noda et al., 1980; Potrich et al., 2009; Valeva et al., 2006; Watanabe et al., 1987). Particularly, crystallographic studies revealed the presence of single, highly conserved phosphocholine (PCho) binding sites on the rim domains of the monomeric F subunit HlgB and the $\alpha$-toxin protomer in the heptameric pore complex (Galdiero and Gouaux, 2004; Olson et al., 1999). These binding sites have been shown by mutational analysis to be required for membrane targeting and cytolytic function of the two toxins (Monma et al., 2004; Walker and Bayley, 1995). It is generally accepted that the leukocidin F subunits and $\alpha$-toxin also function in cell attachment through the engagement of their rim domains with the PC head group in the plasma membrane of target cells (Galdiero and Gouaux, 2004; Valeva et al., 2006; Watanabe et al., 1987). In this report, we demonstrate that the soluble, monomeric and oligomeric pore forms of PVL and $\alpha$-toxin employ two distinct modes to recognize and bind the PC-containing membrane and suggest a novel molecular mechanism for PC-dependent pore formation by members of the $\alpha$-hemolysin cytotoxin subfamily. Furthermore, we find that $n$-tetradecylphosphocholine $\left(\mathrm{C}_{14} \mathrm{PC}\right)$ effectively inhibits cytolysis of primary human immune cells by PVL, $\alpha$-toxin and LukED in vitro, thus demonstrating the potential utility of this antivirulence agent alone or in combination with antibiotics against MRSA.

\section{Results and Discussion}

\section{$\mathrm{C}_{14} \mathrm{PC}$ Binds to the Rim Domain of LukD at Two Adjacent but Distinct Sites}

To better understand the molecular basis for the recognition of PCho by the leukocidin F subunits, we determined the crystal structures of LukD with and without $\mathrm{C}_{14} \mathrm{PC}$ at $1.5 \AA$ and $1.75 \AA$ 
resolution, respectively (Table 1). $\mathrm{C}_{14} \mathrm{PC}$ was selected in the present study as a $\mathrm{PC}$ mimic for its high micellization efficiency due to low critical micelle concentration. The two protein structures are closely similar, with a rmsd for $\mathrm{C} \alpha$ atoms of $0.69 \AA$. The rim domain forms an antiparallel, three-stranded open-face $\beta$-sandwich toppled by two surface-exposed consecutive $\Omega$ loops (residues 180-194, $\Omega 1$ and 195-202, $\Omega 2$ ) (Figure 1A). Two PCho moieties that bind to opposite sides of the $\Omega 2$ loop were unexpectedly discovered upon examination of the difference electron density map in the $\mathrm{C}_{14} \mathrm{PC}$-bound structure (Figure 1B). Average $\mathrm{B}$ factor for these two moieties is $22 \AA^{2}$ and for surrounding solvent molecules and protein atoms $21 \AA^{2}$. The two binding sites are approximately $16 \AA$ apart (Figure 1C). The PCho moiety at the first binding site (site 1) is lodged into a concave pocket similar to one in $\mathrm{HlgB}$ (PDB code $3 \mathrm{LKF}$ ). This pocket is formed by two extended segments (residues 171-173 and 176-179, respectively) and the $\Omega 1-\Omega 2$ junction (191197) (Figures 1A and 1D). The quaternary ammonium group of the PCho moiety engages in a cation $-\pi$ interaction with Trp176 while forming a salt bridge to Glu191 (3.79 $\AA$ ) (Figure 1D). Its $\mathrm{N}$-methyl and methylene groups are in van der Waal contacts $(<4.0 \AA)$ with the main chain atoms of Asn173, Glu191, Leu194 and Gly195 and with the side chains of Asn173, Trp176, Tyr179 and Glu191. Furthermore, the phosphate group is hydrogen bonded through its O2 oxygen to the main chain amide of $\operatorname{Arg} 197$ (2.85 $\AA$ ) on one side of the pocket opening, and the side chain of this residue also wraps around the three other oxygens (Figure 1D). In addition, three water molecules form hydrogen bonds to the $\mathrm{O} 2$ and $\mathrm{O} 3$ oxygens.

Immediately adjacent to site 1 is a novel second binding site (site 2), where the PCho moiety occupies a shallow surface pocket that is framed by the C-terminal half of the $\Omega 2$ loop (residues 198-202) and the $\beta 14-\beta 15$ loop (257-260) and flanked by the side chains of Tyr71, Asn72, Trp256 and Trp261 (Figures 1A and 1D). The quaternary ammonium group is sandwiched between the aromatic rings of Tyr71 and Trp256 through cation- $\pi$ interactions, and the two indole rings of the latter residue and Trp261 interact with each other in an edge-to-face fashion to engage the N-methyl and methylene groups, which also make contacts with the main chain atoms of Ser199, Ser200 and Ser201 and with the side chain of Asn72 (Figure 1D). The phosphate group is secured by a water-mediated hydrogen bonding interaction with the main chain carbonyl of Ser200 $\left(\mathrm{O} 2-\mathrm{H}_{2} \mathrm{O}=2.53 \AA\right.$ and $\left.\mathrm{H}_{2} \mathrm{O}-\mathrm{O}=2.76 \AA\right)$, whose $\mathrm{C} \alpha$ and $\mathrm{C} \beta$ atoms pack against the $\mathrm{O} 1, \mathrm{O} 2$ and O4 oxygens (Figure 1D). 
The highly complementary interactions between the two adjacent binding sites and the PCho moieties are ostensibly important for specific recognition and binding. The buried solvent accessible surface area of PCho is $262 \AA^{2}$ at site 1 and $231 \AA^{2}$ at site 2, which correspond to approximately $77 \%$ and $69 \%$ of the unbound PCho surface area, respectively. The side chains of the conserved Trp176-Arg197 and Ser200-Trp256-Trp261 residues, seen below, that define site 1 and site 2 , respectively, become more ordered upon binding to $\mathrm{C}_{14} \mathrm{PC}$. This side chain flexibility could allow these two adjacent, largely preformed pockets to efficiently accommodate the PCho moieties that have distinct binding poses and residue interactions (Figures 1C and 1D). Consistent with this argument, in differential scanning calorimetry (DSC) experiments, LukD (10 $\mu \mathrm{M})$ was found to unfold in a single cooperative transition, with a midpoint melting temperature $\left(\mathrm{T}_{\mathrm{m}}\right)$ of $51.0^{\circ} \mathrm{C}$, while this $\mathrm{T}_{\mathrm{m}}$ value was shifted to $52.8^{\circ} \mathrm{C}$ in the presence of PCho $(4 \mathrm{mM})$, representing the enhanced thermal stability that accompanies complex formation (Figure 1E). Thus, our results suggest a revised mode of PC recognition and membrane targeting by the rim domain loops.

\section{Binding Mode of $\mathrm{C}_{14} \mathrm{PC}$ to the Rim Domain of LukF-PV}

To validate this binding mode, we cocrystallized LukF-PV with $\mathrm{C}_{14} \mathrm{PC}$ and solved its structure at $1.78 \AA$ resolution (Table 1). In effect, PCho moieties engage the aforementioned two adjacent binding pockets on the rim domain surface (Figures $2 \mathrm{~A}$ and $2 \mathrm{~B}$ ). At site 1, the quaternary ammonium group of the PCho moiety forms both a cation- $\pi$ interaction with Trp176 and a salt bridge to Glu191 (3.84 $\AA$ ); its N-methyl and methylene groups interact with both the main chain atoms of Leu194 and Gly195 and the side chains of Asn173, Trp176, Tyr179, Glu191 and Arg197; and the phosphate group is held in place by a hydrogen bond between its $\mathrm{O} 2$ oxygen and the main chain amide of $\operatorname{Arg} 197$ (2.72 Å), along with the side chain of this residue lying against the O2 and $\mathrm{O} 3$ oxygens (Figure $2 \mathrm{~B}$ ). At site 2 , the quaternary ammonium group participates in a cation- $\pi$ interaction with Trp256 (Figure 2B). Further contacts are made between the N-methyl and methylene groups and both the main chain atoms of Ser199, Asn200 and Leu201 and the side chains of Asn200, Trp256 and Trp261. Polar interactions are also observed between the phosphate and both the main chain atom of Asn200 and the side chain of Asn202 (Figure 2B).

The solvent accessible surface area of PCho buried by the LukF-PV interaction comprises 264 $\AA^{2}(79 \%)$ at site 1 and $214 \AA^{2}(63 \%)$ at site 2 . DSC measurements reveal that the $\mathrm{T}_{\mathrm{m}}$ of LukF-PV increased from $50.3^{\circ} \mathrm{C}$ to $52.3^{\circ} \mathrm{C}$ when it was bound to PCho. We note that the PCho moiety at 
site 2 has considerably higher average B factor and poorer electron density than that at site 1 ( 70 $\AA^{2}$ as compared with $31 \AA^{2}$ ), suggesting that the former moiety is less tightly bound and exhibits greater spatial or temporal disorder. In LukD, the aromatic side chain of Tyr71 contributes to the cation $-\pi$ binding interaction to site 2 (see Figure 1D), whereas the corresponding residue in LukFPV (Thr71) cannot make this interaction (Figure 2C), likely accounting for the lower affinity binding site. The critical functional role of this affinity difference is highlighted by the observation that replacement of Thr71 with a tyrosine endows LukF-PV with the ability to bind human erythrocytes and acquire hemolytic activity when combined with the S subunit of HlgAB (Yokota and Kamio, 2000). Therefore, the elaborate structural features of the two distinct, adjacent PCho binding sites on the leukocidin F subunits may be explained by a selective pressure for membrane PC itself acting as their cell surface receptor.

\section{$\mathrm{C}_{14}$ PC Binding by Monomeric $\alpha$-Toxin ${ }^{\mathrm{H} 35 \mathrm{~A}}$}

To discern the mechanism in the attachment of $\alpha$-hemolysin subfamily members to host cells, we determined the $2.80 \AA$ crystal structure of $\mathrm{C}_{14} \mathrm{PC}$ in complex with the monomeric His $35 \rightarrow$ Ala mutant of $\alpha$-toxin ( $\alpha$-toxin ${ }^{\mathrm{H} 35 \mathrm{~A}}$ ) (Liang et al., 2009) (Table 1). The asymmetric unit contains two nearly identical protein monomers (rmsd for $\mathrm{C}_{\alpha}$ atoms of $0.44 \AA$ ), each bound to two PCho moieties (Figure 3A). These moieties occupy the two adjacent binding pockets described above (Figure 3B). At site 1, which is similar to that on the $\alpha$-toxin protomer in the heptameric pore complex (Galdiero and Gouaux, 2004), the quaternary ammonium group of the PCho moiety makes a cation $-\pi$ interaction with Trp179 (Figure 3C). Its N-methyl and methylene groups are surrounded by the main chain atoms of Met197 and Lys198 and by the side chains of Asn176, Gln177, Trp179, Tyr182, Gln194, Met197 and Arg200. Importantly, the O2 oxygen of the phosphate group establishes a strong hydrogen bond to the main chain amide of Arg200 (2.64 $\AA$ ) that also makes side chain contacts with the $\mathrm{O} 2$ and $\mathrm{O} 4$ oxygens (Figure 3C). At site 2, the quaternary ammonium group forms a cation $-\pi$ interaction with Trp260, and the N-methyl and methylene groups interact with the main chain atoms of Gly202, Ser203 and Met204 and with the side chains of Ala73, Asn74 and Trp265 (Figure 3B). The phosphate group is clearly visible in the electron density map, although the fine detail of the oxygens is not clear. There are contacts of $3.19 \AA$ between the phosphate and Ser203 and of $3.62 \AA$ between the phosphate and Trp260 (Figure 3C). Upon binding to $\alpha$-toxin ${ }^{\mathrm{H} 35 \mathrm{~A}}$, PCho buries $268 \AA^{2}(79 \%)$ and $203 \AA^{2}(61 \%)$ of its 
solvent accessible surface area at site 1 and site 2, respectively. DSC analysis shows that the addition of PCho increased the $\mathrm{T}_{\mathrm{m}}$ of $\alpha$-toxin ${ }^{\mathrm{H} 35 \mathrm{~A}}$ from $50.8^{\circ} \mathrm{C}$ to $52.4^{\circ} \mathrm{C}$. We also observed that the average B factor for the PCho moiety at site 2 is significantly higher than that at site $1\left(112 \AA^{2}\right.$ as compared with $75 \AA^{2}$ ). As discussed in the preceding section, the decreased affinity of site 2 for PCho may arise from the presence of an alanine at position 73 (corresponding to LukD Tyr71) (Figure 2C).

Closer examination of the positions and conformations of the two PCho moieties in the superimposed cocrystal structures of $\mathrm{C}_{14} \mathrm{PC}$ with $\alpha$-toxin ${ }^{\mathrm{H} 35 \mathrm{~A}}$, LukD and LukF-PV revealed remarkable similarities. There are few differences in the positions of the five key binding site amino acid side chains (Trp179, Arg200, Ser203, Trp260 and Trp265 in $\alpha$-toxin; equivalent to Trp176, Arg197, Ser/Asn200, Trp256 and Trp261 in LukD and LukF-PV) in these structures. The three Trp side chains provide two important anchor points for locating the PCho moieties in the two adjacent binding sites, and the Arg and Ser/Asn residues are critical determinants in the binding of the two phosphate groups. Evidently, PC recognition specificity is achieved by a combination of stacking and hydrogen bonding interactions, and van der Waals contacts. Our study shows that membrane PC serves as the common receptor for $\alpha$-toxin and the leukocidin F subunits, in agreement with previous observations (Galdiero and Gouaux, 2004; Valeva et al., 2006; Watanabe et al., 1987). The presence of the two adjacent PC binding sites on the toxin monomer is consistent with the estimated cross-sectional areas of the PC-bound rim domain $\left(\sim 150 \AA^{2}\right)$ and one PC molecule ( $70 \AA^{2}$ ) (Nagle and Tristram-Nagle, 2000).

Intermolecular contacts between the above two $\alpha$-toxin ${ }^{\mathrm{H} 35 \mathrm{~A}}$ monomers comprising the crystal asymmetric unit are formed by residues in the $\beta$-sandwich domain (Figure 3D). Comparison of the conformation of these contact residues with their interprotomeric equivalents in the unliganded and $\mathrm{C}_{14} \mathrm{PC}$-bound heptamers of wild-type $\alpha$-toxin (PDB code 7AHL; see Figure 5) reveals no local conformational changes involving the main-chain or side-chain atoms. Superposition of the $\alpha-$ toxin $^{\mathrm{H} 35 \mathrm{~A}}$ dimer onto two adjacent promoters in the above two wild-type toxin heptamers yields overall $\mathrm{C} \alpha$ rmsds of 0.99 and $0.95 \AA$, respectively, indicating their structural similarity. Dimer interfaces have similar buried surface area values, from 2,061 to $2,171 \AA^{2}$. It is also important to note that the crystal structure of unliganded $\alpha$-toxin ${ }^{\mathrm{H} 35 \mathrm{~A}}$ (PDB code 4YHD) lacks the aforementioned intermolecular contacts between six independent monomers in the asymmetric 
unit. In this structure, both the amino latch and prestem regions have well-defined density with the exception of the six-residue prestem loop and pack against the $\beta$-sandwich core of the protein. By contrast, these two regions are apparently disordered in the $\mathrm{C}_{14} \mathrm{PC}$-bound structure. Our results suggest that $\alpha$-toxin ${ }^{\mathrm{H} 35 \mathrm{~A}}$ may be trapped in a PC-bound dimeric state, which may represent an onpathway intermediate in the assembly of the heptameric pore complex.

Given their expected importance in membrane targeting, the five key PC binding site residues are highly conserved or invariant in both $\alpha$-toxin and the leukocidin F subunits but are absent in the S subunits, with the exception of a histidine at position 176 in LukB (Figure 2C). Of particular importance, LukB exists as a soluble heterodimeric complex with LukA (DuMont et al., 2014). This finding is consistent with the central role of the conserved Trp176 of the three other F subunits in their binding to the PC bilayer (Olson et al., 1999; Valeva et al., 2006; Watanabe et al., 1987). (and this study). We therefore propose that the binding of the F subunit to the PC-rich membrane is allosterically coupled to heterodimerization with its $\mathrm{S}$ subunit counterpart. Likewise, membrane binding by $\alpha$-toxin, mediated by PC and/or ADAM10, irrevocably commits the monomers to dimerization. The remarkable high degree of conservation of the two adjacent PC binding sites among $\alpha$-toxin and the $F$ subunits reflects a strong selective pressure on the ability of these two sites to help anchor toxin monomers to the cell surface and to form intermolecular contacts that prime the ensuing formation of the oligomeric, membrane-inserted pore complex.

In summary, the bivalent rim domain interaction with PC provides a mechanism by which soluble toxin monomers can recognize and target the PC-containing membrane, thereby promoting dimer-nucleated pore assembly. The relatively low affinity of PC-mediated binding may facilitate subsequent establishment of the final geometry of the oligomeric pore complex, which we discuss below. $\alpha$-Toxin and the leukocidin $\mathrm{S}$ subunits also bind their specific proteinaceous receptors (Alonzo et al., 2013; Gauduchon et al., 2001; Spaan et al., 2017), and these interactions likely work in concert with the PC targeting mechanism to modulate toxin binding, pore formation and cytotoxicity. Finally, and most importantly, structural elucidation of the two conserved, adjacent PC binding pockets on $\alpha$-toxin and the leukocidin F subunits will guide the rational development of PC analogs as decoy receptors that effectively divert the cytotoxin away from susceptible cells.

\section{Structure of the $\mathrm{C}_{14} \mathrm{PC}$-Bound PVL Heterooctamer}


In light of previous studies suggesting that PC plays a crucial role in the assembly and function of the $\alpha$-toxin heptamer (Galdiero and Gouaux, 2004; Valeva et al., 2006), we cocrystallized the LukS-PV and LukF-PV proteins with $\mathrm{C}_{14} \mathrm{PC}$ in the presence of n-octyl- $\beta$-glucoside. The structure of the complex was solved at $2.04 \AA$ resolution by molecular replacement (Table 1). The asymmetric unit contains one LukF-PV/LukS-PV heterodimer and a single LukS-PV molecule. The heterodimer interacts with three crystallographic 4-fold symmetry-related copies of itself to generate a heterooctamer (Figures 4A and 4B). In this $\beta$-barrel pore complex, four LukF-PV protomers (denoted A, C, E and G) and four LukS-PV protomers (B, D, F and H) are arranged in an alternating fashion around the central axis of pore, in which the stem domain folds into an antiparallel $\beta$-barrel composed of $16 \beta$-strands. We could not discern electron density corresponding to the bottom third of the stem domain in our structure. Two distinct interfaces between neighboring protomers involve residues that are distributed among the amino latch region and the $\beta$-sandwich and stem domains, and bury 2,644 $\AA^{2}$ and 1,902 $\AA^{2}$ of solvent accessible surface area, respectively. The electron density map revealed clearly the presence of PCho moieties at three distinct binding sites on each of the four protomeric units of the PVL heterooctamer (Figures 4C and 4D). The two adjacent binding sites are essentially the same as those on the abovedescribed toxin monomer, whereas the other, novel site lies at the interface between the rim domain of a LukF-PV protomer (e.g., protomer A) and the proximal stem domain regions of protomers $\mathrm{G}$ and $\mathrm{H}$. The average $\mathrm{B}$ factor for the three PCho moieties is significantly higher than that for the surrounding residues (60 $\AA^{2}$ as compared with $31 \AA^{2}$ ), possibly due to greater disorder and/or subunitary occupancy. Superposition of the PVL hetereooctamer bound to $\mathrm{C}_{14} \mathrm{PC}$ onto the unliganded HlgAB (PDB code 3B07) and LukGH (PDB code 4TW1) heterooctamers yields C $\alpha$ rmsds of 0.67 and $1.14 \AA$, respectively, suggesting that the PVL pore does not undergo large conformational changes upon binding to $\mathrm{C}_{14} \mathrm{PC}$.

The three PCho binding sites on a single protomeric unit are contained within a wateraccessible crevice between the inner surface of the rim domain and the upper portion of the stem domain (Figures 4A and 4B). As noted above, the two adjacent sites correspond to those on the rim domain of monomeric LukF-PV (Figure 4D; also see Figure 2B), differing only in the presence of more stabilizing molecular contacts at site 2 on the heterooctamer. Specifically, the quaternary ammonium group of the PCho moiety makes a cation $-\pi$ interaction with Trp256, and the indole ring of this residue establishes an edge-to-face interaction with the indole ring of Trp261 to pack 
against the N-methyl and methylene groups, which are also in contact with the main chain atoms of Thr71, Ser199, Asn200 and Leu201 and with the side chain of Ile72 (Figure 4E). At site 3, the aromatic ring of Tyr137 of protomer $\mathrm{H}$ forms a cation- $\pi$ interaction with the quaternary ammonium group and stacks against the N-methyl and methylene groups that are also lined with the side chain of Ile135 of protomer H (Figure 4E). Furthermore, the O3 oxygen of the phosphate group hydrogen bonds to the main chain amide of Gly175 of protomer A (2.65 $\AA$ ), and the O1 and O3 oxygens engage both the main chain atoms of Asn174 and Gly175 of protomer A and the side chains of Met172 of protomer A and Gln112 of protomer G (Figure 4E). The solvent accessible surface area of PCho buried upon complex formation is $258 \AA^{2}(77 \%)$ at site $1,189 \AA^{2}(57 \%)$ at site 2 and $224 \AA^{2}(65 \%)$ at site 3 .

Our results suggest that multivalent binding of the PVL heterooctamer to PC on the membrane surface leads to localized defects in the lipid bilayer and thus promotes the insertion of amphipathic $\beta$-hairpins to produce the $\beta$-barrel piercing the bilayer. Critical residues Tyr137 of LukS-PV and Gly175 of LukF-PV at site 3 are invariant in the leukocidin S and F subunits, respectively (Figure 2C), underscoring their functional importance. Furthermore, three similar PC binding pockets also exist in protomers of the $\mathrm{C}_{14} \mathrm{PC}$-bound $\alpha$-toxin heptamer described below.

\section{Binding Mode of $\mathrm{C}_{14} \mathrm{PC}$ to the $\alpha$-Toxin Heptamer}

To evaluate the binding of the $\alpha$-toxin heptamer to the PC head group in a membrane-mimicking environment, we determined the crystal structure of its complex with $\mathrm{C}_{14} \mathrm{PC}$ at $2.35 \AA$ resolution (Table 1). In this structure, three PCho moieties are bound to each of the seven protomeric units in the water-accessible crevice between the rim and stem domains (Figures 5A and 5B). The indole ring of Trp179 mediates three-way interactions with these three moieties (Figure 5C). Their conformations are clearly defined in three partially overlapping but distinct binding pockets of the crevice (Figure 5D). One pocket corresponds to site 1 on the toxin monomer described above, while the other two are novel heptamer-specific binding sites (see below). The average B factor for the three PCho moieties is $60 \AA^{2}$ and for surrounding protein atoms $33 \AA^{2}$. The structure of the $\mathrm{C}_{14} \mathrm{PC}$-bound heptamer is very similar to that of the unliganded heptamer (PDB code 7AHL; rmsd for $\mathrm{C}_{\alpha}$ atoms of $0.48 \AA$ ), with only minor changes in the positions of side chains involved in direct contact with $\mathrm{C}_{14} \mathrm{PC}$. The pairwise rmsds between protomers $\mathrm{A}-\mathrm{G}$ in the heptamer span a range from 0.13 to $0.17 \AA$ for $\mathrm{C}_{\alpha}$ atoms. The PCho moieties at each of the three binding sites have 
essentially identical conformation and orientation in each of the seven protomeric units, with average rmsds of $0.34 \AA$ for the first pocket, $0.32 \AA$ for the second pocket and $0.41 \AA$ for the third pocket. For this reason, the following structural analysis of these binding pockets applies to all of the protomeric units.

The first pocket, defined by $\operatorname{Trp} 179$ and Arg200, is the same as that on monomeric $\alpha$-toxin ${ }^{\mathrm{H} 35 \mathrm{~A}}$ (see Figure 3), albeit the hydrogen bond between the phosphate group of the PCho moiety and the main chain amide of Arg200 is considerably longer and weaker in the latter (Figure 5E). The second pocket lined by all four residues on strand $\beta 12$ of the rim domain snugly accommodates the PCho moiety (Figures 5D and 5E). It mediates a network of van der Waals contacts involving the main chain atoms of Gly180 and Pro181 and the aromatic rings of Trp179 and Tyr182, forming hydrogen bonds via its hydroxyl group towards the O3 oxygen of the phosphate group (2.69 $\AA$ ) and via its $\mathrm{O} 2$ oxygen with the main chain amide of Gly180 (2.84 $\AA$ ) while in the cis rotamer.

The third pocket is located at the interface between the rim domain of protomer $\mathrm{A}$ and the proximal stem domain regions of protomers $\mathrm{E}$ and $\mathrm{F}$ (Figure 5E), in contrast to the other pockets that are constituted solely by residues from the rim domain. The third pocket is formed by residues Asn178 and Trp179 from the rim domain of protomer A, by Leu116 and Tyr118 from the stem domain of protomer E and by Tyr112, Ser114, Ile142, Gly143 and His144 from the stem domain of protomer $\mathrm{F}$ (Figure $5 \mathrm{E}$ ). The indole ring of $\operatorname{Trp} 179$ is situated to produce a cation $-\pi$ interaction with the quaternary ammonium group of the PCho moiety (Figure 5E). The N-methyl and methylene groups participate in extensive contacts with the main chain atoms of Gly143 and Asn178 and with the side chains of Tyr112, Ser114 and Ile142. The PCho moiety is further stabilized by a hydrogen bond between the O3 oxygen of the phosphate group and the ND1 atom of His144 (2.78 $\AA$ ) and by contacts between the O1, O2 and O3 oxygens and the side chains of Leu116, Tyr118 and His144 (Figure 5E). The solvent accessible surface areas buried upon binding of the PCho moieties to the first, second and third pockets are $260 \mathrm{~A}^{2}(76 \%), 207 \mathrm{~A}^{2}(60 \%), 285$ $\mathrm{A}^{2}(83 \%)$, respectively.

These results strengthen the hypothesis that multivalent binding of the PC bilayer by the $\alpha$ toxin heptamer may help overcome the energetic barrier to deformation of the membrane during assembly of the $\beta$-barrel pore lining, thereby driving the prepore-to-pore conversion. Indeed, replacement of Trp179 and Arg200 with alanines in $\alpha$-toxin is known to lead to an arrested prepore state in which only the top half of the cytolytic $\beta$-barrel pore has formed (Sugawara et al., 2015). 
Together with analysis of intermediate stages of the $\alpha$-toxin assembly process with engineered disulfide bonds (Kawate and Gouaux, 2003), our study also suggests that the interaction between the $\alpha$-toxin prepore and the PC head group may induce a large conformational change in the prestem region, which is essential for pore formation.

\section{Structure of the $\alpha$-Toxin ${ }^{\mathrm{H} 35 \mathrm{~A}}$ Heptamer in Complex with $\mathrm{C}_{14} \mathrm{PC}$}

In the $\alpha$-toxin pore structure, His35 is located in the crucial interprotomeric contact region (Song et al., 1996), and nonconservative replacements at this position (including H35A) have been shown to abolish heptamer formation and thus cytolytic activity and lethal toxicity (Jursch et al., 1994; Krishnasastry et al., 1994; Menzies and Kernodle, 1994). In light of our findings that the PC bilayer binding might promote both the oligomerization of $\alpha$-toxin monomers and the structural rearrangements that accompany the prepore-to-pore conversion, we hypothesized that a high concentration of $\mathrm{C}_{14} \mathrm{PC}$ could facilitate the assembly of the $\alpha$-toxin ${ }^{\mathrm{H} 35 \mathrm{~A}}$ pore complex. To directly test this hypothesis, we have determined the structure of the $\alpha$-toxin ${ }^{\mathrm{H} 35 \mathrm{~A}}$ heptamer crystallized in the presence of $25 \mathrm{mM} \mathrm{C}_{14} \mathrm{PC}$ (see Experimental Procedures) at $2.5 \AA$ resolution (Table 1 and Figure 5F). In this mutant pore complex, PCho moieties bind in the first and second pockets described above on the rim domain of each protomer. In essence, the $\mathrm{C}_{14} \mathrm{PC}$-bound structures of the $\alpha$-toxin ${ }^{\mathrm{H} 35 \mathrm{~A}}$ and wild-type heptamers are nearly identical, with rmsds of $0.04-1.42 \AA$ over 2,051 C $\alpha$ atoms. The positions and conformations of the two PCho moieties are also similar. However, $\mathrm{C}_{14} \mathrm{PC}$ does not bind to the aforementioned interprotomer pocket on the $\alpha$-toxin ${ }^{\mathrm{H} 35 \mathrm{~A}}$ pore, while B factors for this mutant pore are considerably higher than those for the wild-type one (24-201 $\AA^{2}$ as compared with 13-73 $\AA^{2}$ ), consistent with the pronounced effect of the H35A mutation on cytotoxicity (Liang et al., 2009). These results support our hypothesis that the PC-rich membrane acts as a critical effector of oligomerization and pore formation by $\alpha$-toxin.

In summary, despite their different subunit composition and stoichiometry, $\alpha$-toxin and the leukocidins likely follow an evolutionarily conserved PC-dependent pore assembly pathway, involving the initial membrane binding of toxin monomers, dimerization and oligomerization, and the prepore-to-pore transition and membrane perforation. Importantly, atomic-level insight of the toxin oligomer-PC interactions obtained here will facilitate the development of PC analogs that antagonize pore formation and thus block the cytolytic effects of this subfamily of proteins. 


\section{Inhibition of the Cytotoxicity of LukED, PVL and $\alpha$-Toxin by $\mathrm{C}_{14} \mathrm{PC}$}

The presence of the conserved PC binding sites in the leukocidins and $\alpha$-toxin (see above) suggests that PC mimetic compounds may confer protection from toxin-mediated killing of primary human immune cells. Therefore, flow cytometry experiments were conducted to first evaluate the ability of $\mathrm{C}_{14} \mathrm{PC}$ to diminish the cytolytic activity of LukED in Jurkat cells expressing CCR5. This Jurkat cell line has been shown to be susceptible to the toxin (Alonzo et al., 2013). LukED at a concentration of $2.5 \mu \mathrm{g} / \mathrm{mL}$ resulted in $\sim 80 \%$ killing of Jurkat cells within $1 \mathrm{~h}$ at $37^{\circ} \mathrm{C}$ (Figure $6 \mathrm{~A}$ ). We found that $\mathrm{C}_{14} \mathrm{PC}$ inhibited the lysis in a concentration-dependent manner, with $\mathrm{IC}_{50}$ values of 15-25 $\mu \mathrm{M}$ (Figure 6A). In sharp contrast, PCho does not have appreciable inhibitory activity. We conclude that $\mathrm{C}_{14} \mathrm{PC}$ produces effective toxin inhibition by presenting multiple copies of the PC head group on its micellar surface, in accordance with previous observations (Valeva et al., 2006).

To determine the capacity of $\mathrm{C}_{14} \mathrm{PC}$ to abrogate LukED cytotoxicity toward primary human leukocytes expressing CCR5 and CXCR1 chemokine receptors in vitro, LukED at concentrations of 2.5 and $5 \mu \mathrm{g} / \mathrm{ml}$ was first preincubated with $50 \mu \mathrm{M} \mathrm{C}_{14} \mathrm{PC}$ at $4{ }^{\circ} \mathrm{C}$, and was subsequently added to PBMCs labelled with specific cell surface markers. After $1-1.5 \mathrm{~h}$ at $37^{\circ} \mathrm{C}$, the cells were stained with fixable viability dye eFluor 506 and analyzed by flow cytometry. Inhibition of LukED by $\mathrm{C}_{14} \mathrm{PC}$ was assessed by determining the relative abundance of viable cells after challenge with the toxin or media. As expected, $\mathrm{CD} 14^{+}$monocytes were significantly absent by 2.5 and $5 \mu \mathrm{g} / \mathrm{mL}$ of LukED (Figure 6D), while pretreatment with $50 \mu \mathrm{M} \mathrm{C}_{14} \mathrm{PC}$ produced a $70-90 \%$ protective effect against monocyte lysis (Figures 6B and 6D). Likewise, $50 \mu \mathrm{M} \mathrm{C}_{14} \mathrm{PC}$ efficiently blocked the lysis of $\mathrm{CD}^{+}$effector memory $\mathrm{T}$ cells by $50-75 \%$ (Figures $6 \mathrm{C}$ and $6 \mathrm{E}$ ) and $\mathrm{CD} 8^{+} \mathrm{CCR} 5^{+} \mathrm{T}$ cells by $50-$ 95\% (Figure 6F). Moreover, inhibition of the cytolytic action of LukED by $50 \mu \mathrm{M} \mathrm{C}_{14} \mathrm{PC}$ also rescued $50-85 \%$ of NK cells (Figure 6G), which are highly susceptible to the toxin due to their surface expression of CXCR1 (Alonzo et al., 2013). These results demonstrate that $\mathrm{C}_{14} \mathrm{PC}$ can confer broad-spectrum protection against LukED-mediated killing of target host cells by virtue of its inhibitory effect on the interaction between the toxin and membrane PC.

We next sought to assess the ability of $\mathrm{C}_{14} \mathrm{PC}$ to inhibit the cytolytic activities of PVL and $\alpha$ toxin using the in vitro cell viability assay described above. Addition of $10 \mathrm{ng} / \mathrm{mL}$ of PVL led to nearly complete lysis of monocytes after $1.5 \mathrm{~h}$ of incubation at $37^{\circ} \mathrm{C}$ (Figure $7 \mathrm{~A}$ ). Pretreatment with $100 \mu \mathrm{M} \mathrm{C}_{14} \mathrm{PC}$ suppressed the lysis by $90 \%$ (Figures $7 \mathrm{~A}$ and $7 \mathrm{~B}$ ). Similarly, $\alpha$-toxin at 
concentrations of 30 and $100 \mathrm{ng} / \mathrm{mL}$ caused $75-90 \%$ lysis of monocytes and $\sim 50 \%$ lysis of CD3 ${ }^{+}$ $\mathrm{T}$ cells after incubation at $37^{\circ} \mathrm{C}$ for $24 \mathrm{~h}$, while $100 \mu \mathrm{M} \mathrm{C}_{14} \mathrm{PC}$ reduced the cytotoxic activity of the toxin by $75-90 \%$ (Figures $7 \mathrm{C}$ and $7 \mathrm{D}$ ). We conclude that $\mathrm{C}_{14} \mathrm{PC}$ is a broad-spectrum smallmolecule inhibitor of the $\alpha$-hemolysin subfamily of toxins and that membrane PC contributes to the mechanism of their cytolytic action.

\section{Implication for MRSA Drug Discovery}

The high prevalence of multidrug-resistant S. aureus and its remarkable pathogenic potential are creating a crisis in modern healthcare due to the limited therapeutic options available, the toll of severe disease and mortality it inflicts, and the enormous cost of inpatient care to which it contributes (Chambers and Deleo, 2009; Otto, 2010). The ability of MRSA to form biofilms on necrotic tissues and medical devices is also an important virulence mechanism that complicates infections (Jones et al., 2001; Otto, 2008). As antibiotics are becoming less effective, disarming the major virulence mechanisms of MRSA strains has potential to become an alternative, viable therapeutic approach aimed at limiting host tissue damage while aiding immune clearance. The $\alpha$-hemolysin subfamily of cytotoxins are prime targets for novel therapeutics, owing to their critical roles in inactivating host immune defenses, destroying tissue barriers and modulating inflammatory responses (Diep et al., 2006; Otto, 2010). Currently, neutralizing antibodies targeting $\alpha$-toxin are in clinical trials (Hua et al., 2015; Le et al., 2016). Given the variability of MRSA immune evasion determinants, such single-target drugs are most likely to be inadequate to achieve a therapeutic effect (Sause et al., 2016). Our structural elucidation of the conserved role of membrane PC in pore formation by members of this subfamily offers new opportunities for concurrent intervention of their pathology via blocking both toxin binding to host cells and pore complex assembly. As a result of our combined structural biology and pharmacological approach, we have been able to demonstrate that $\mathrm{C}_{14} \mathrm{PC}$ is a novel broad-spectrum inhibitor of the leukocidins and $\alpha$-toxin in vitro. In light of the safety of miltefosine (hexadecylophosphocline, $\mathrm{C}_{16} \mathrm{PC}$ ), an oral drug used for the treatment of leishmaniasis (Dorlo et al., 2012), it is reasonable to surmise that the $\mathrm{C}_{14} \mathrm{PC}$ will likewise be well tolerated in humans. Considering its multi-target mechanism of action and low production costs, $\mathrm{C}_{14} \mathrm{PC}$ could potentially be developed as a prophylactic and therapeutic agent against MRSA.

\section{Experimental Procedures}




\section{Chemicals}

All chemicals used were of analytical grade. Unless otherwise indicated, chemicals were purchased from Sigma-Aldrich. Detergents were from Anatrace.

\section{Cloning and Protein Purification}

The full-length LukD (residues 1-301), LukE (1-283), LukF-PV (1-301), LukS-PV (1-284) and $\alpha$-toxin (1-293) constructs, excluding their signal peptides, were subcloned individually into a modified pET3a vector (Novagen). Site-directed mutagenesis was carried out using the Kunkel method. All constructs were verified by DNA sequencing. E. coli BL21(DE3)pLysS cells transformed with each plasmid were grown at $37^{\circ} \mathrm{C}$ in $\mathrm{LB}$ medium until the $\mathrm{A}_{600}$ was between 0.6 and 0.8. IPTG was then added to a final concentration of $0.5 \mathrm{mM}$, and incubation was continued for $24 \mathrm{~h}$ at $16^{\circ} \mathrm{C}$. Cells were harvested by centrifugation, suspended in $50 \mathrm{mM}$ sodium acetate $(\mathrm{pH}$ 5.4), 25\% sucrose, $5 \mathrm{mM}$ EDTA and $5 \mathrm{mM}$ DTT and lyzed at $4^{\circ} \mathrm{C}$ using an Avestin Emulsiflex C3 homogenizer. Inclusion bodies were isolated by centrifugation, washed twice with the same buffer and subsequently incubated overnight at $4^{\circ} \mathrm{C}$ in $50 \mathrm{mM}$ sodium acetate (pH 5.4), $5 \mathrm{mM}$ DTT and $6 \mathrm{M}$ guanidine- $\mathrm{HCl}$ or $8 \mathrm{M}$ urea. Insoluble material was removed by centrifugation, and the protein solution was then dialyzed for 2 days at $4^{\circ} \mathrm{C}$ against three changes of buffer A ( $50 \mathrm{mM}$ sodium acetate [pH 5.4] and $1 \mathrm{mM}$ EDTA). After removal of the insoluble material by centrifugation, the refolded recombinant toxin was loaded onto a CM-Sepharose CL-6B column equilibrated with buffer $\mathrm{A}$ and eluted using a linear gradient from 0 to $1 \mathrm{M} \mathrm{NaCl}$. Fractions containing the toxin were pooled, dialyzed against buffer A, concentrated and loaded onto a GE Mono S 5/50 GL equilibrated with buffer $\mathrm{A}$, and the toxin was eluted using a linear gradient from 0 to $0.5 \mathrm{M} \mathrm{NaCl}$. The toxin was further purified using size exclusion chromatography on a GE Superdex 200 10/300 GL equilibrated with $50 \mathrm{mM}$ sodium acetate $(\mathrm{pH}$ 5.4) containing $100 \mathrm{mM} \mathrm{NaCl}$. Fractions containing the toxin were pooled, concentrated to $\sim 20 \mathrm{mg} / \mathrm{mL}$ and stored at $-80^{\circ} \mathrm{C}$ until use. The concentration of the toxin in purified preparations was determined through UV absorbance measurements.

\section{Crystallization}

All crystallization experiments were performed at room temperature using the hanging drop-vapor diffusion method by mixing $1 \mu \mathrm{L}$ of protein solution with an equal volume of reservoir solution. Crystals of LukD were grown from a protein solution $(12 \mathrm{mg} / \mathrm{mL})$ in $10 \mathrm{mM}$ sodium acetate $(\mathrm{pH}$ 
5.4) and a reservoir solution containing 20\% PEG MME 2000, $10 \mathrm{mM} \mathrm{NiCl}_{2}, 0.1 \mathrm{M}$ Tris-HCl (pH 8.5). For data collection, the crystals were cryoprotected with $15 \%$ glycerol in the mother liquor and then flash-cooled in liquid nitrogen. The $\mathrm{C}_{14} \mathrm{PC}-\mathrm{LukD}$ complex was crystallized from a protein solution $(10 \mathrm{mg} / \mathrm{mL})$ in $10 \mathrm{mM}$ sodium acetate $(\mathrm{pH} 5.4), 10 \mathrm{mM} \mathrm{C}_{14} \mathrm{PC}, 30 \mathrm{mM}$ n-octyl$\beta$-D-glucoside $(\beta \mathrm{OG})$ and a reservoir solution containing $28 \%$ PEG 400, $0.2 \mathrm{M} \mathrm{MgCl}, 0.1 \mathrm{M}$ HEPES (pH 7.5). The crystals were flash-cooled by plunging directly into liquid nitrogen. Crystals of LukF-PV complexed with $\mathrm{C}_{14} \mathrm{PC}$ were grown from a protein solution $(10 \mathrm{mg} / \mathrm{mL})$ in $10 \mathrm{mM}$ sodium acetate ( $\mathrm{pH} 5.4$ ), $10 \mathrm{mM} \mathrm{C}{ }_{14} \mathrm{PC}, 30 \mathrm{mM} \beta \mathrm{OG}$ and a reservoir solution containing $2.6 \mathrm{M}$ ammonium sulfate, 5\% PEG 400, 0.1 M HEPES ( $\mathrm{pH} 8.5$ ). The crystals were flash-cooled in liquid nitrogen. The $\mathrm{C}_{14} \mathrm{PC}-\alpha$-toxin ${ }^{\mathrm{H} 35 \mathrm{~A}}$ complex was crystallized from a protein solution $(10 \mathrm{mg} / \mathrm{mL})$ in $10 \mathrm{mM}$ sodium acetate (pH 5.4), $5 \mathrm{mM} \mathrm{C}{ }_{14} \mathrm{PC}, 40 \mathrm{mM} \beta O G, 0.4 \mathrm{mM}$ Deoxy-Big CHAP and a reservoir solution containing $1.5 \mathrm{M}$ ammonium sulfate, $0.25 \mathrm{M}$ potassium sodium tartrate, $0.1 \mathrm{M}$ sodium citrate $(\mathrm{pH}$ 6.0). The crystals were transferred into a stabilizing solution containing 2.25 $\mathrm{M}$ ammonium sulfate, $5 \%$ glycerol, $20 \mathrm{mM} \mathrm{C}_{14} \mathrm{PC}, 0.1 \mathrm{M}$ sodium citrate $(\mathrm{pH} 6.0)$ and then allowed to equilibrate against $3 \mathrm{M}$ ammonium sulfate for $1 \mathrm{~h}$ at room temperature prior to flash freezing in liquid nitrogen. The PVL heterooctamer in complex with $\mathrm{C}_{14} \mathrm{PC}$ was crystallized from a protein solution (6.7 mg LukF-PV/mL and $6.3 \mathrm{mg} \mathrm{LukS-PV/mL)} \mathrm{in} 10 \mathrm{mM}$ sodium acetate (pH 5.4), 15 $\mathrm{mM} \mathrm{C}_{14} \mathrm{PC}, 40 \mathrm{mM} \beta \mathrm{OG}$ and a reservoir solution containing $0.16 \mathrm{M}$ magnesium formate. The crystals were transferred into a dehydrating solution containing $2.7 \mathrm{M}$ ammonium sulfate, $20 \mathrm{mM}$ $\mathrm{C}_{14} \mathrm{PC}$ and then allowed to equilibrate against $3 \mathrm{M}$ ammonium sulfate for $3 \mathrm{~h}$ at room temperature prior to flash freezing in liquid nitrogen. Crystals of the $\alpha$-toxin heptamer- $\mathrm{C}_{14} \mathrm{PC}$ complex were grown from a protein solution $(8 \mathrm{mg} / \mathrm{mL})$ in $10 \mathrm{mM}$ sodium acetate $(\mathrm{pH} \mathrm{5.4}), 15 \mathrm{mM} \mathrm{C}{ }_{14} \mathrm{PC}, 30$ $\mathrm{mM} \beta \mathrm{OG}$ and a reservoir solution containing $2 \mathrm{M}$ ammonium sulfate, $0.2 \mathrm{M}$ potassium sodium tartrate, 0.1 M sodium citrate ( $\mathrm{pH}$ 6.0). The crystals were flash-frozen in liquid nitrogen. The $\alpha-$ toxin ${ }^{\mathrm{H} 35 \mathrm{~A}}$ heptamer in complex with $\mathrm{C}_{14} \mathrm{PC}$ was crystallized from a protein solution $(10 \mathrm{mg} / \mathrm{mL})$ in $10 \mathrm{mM}$ sodium acetate ( $\mathrm{pH} 5.4), 25 \mathrm{mM} \mathrm{C}_{14} \mathrm{PC}, 40 \mathrm{mM} \beta \mathrm{OG}$ and a reservoir solution containing 1.9 M ammonium sulfate, $0.25 \mathrm{M}$ potassium sodium tartrate, $0.1 \mathrm{M}$ sodium citrate ( $\mathrm{pH}$ 5.2). The crystals were flash-cooled in liquid nitrogen.

\section{X-Ray Data Processing and Crystallographic Refinement}


Diffraction data were collected at $100 \mathrm{~K}$ at beamline X4C at the National Synchrotron Light Source at Brookhaven National Laboratory, at the Cornell High Energy Synchrotron Source (CHESS) beamline F1 and at the Stanford Synchrotron Radiation Lightsource (SSRL) beamline 9-2. The diffraction data were processed with HKL-2000 (Otwinowski and Minor, 1997). Initial phases were determined by molecular replacement using Phaser (McCoy et al., 2007) with respective models of HlgB (PDB code 1LKF), LukF-PV (1PVL), $\alpha$-toxin ${ }^{\mathrm{H} 35 \mathrm{~A}}$ (4YHD), the HlgAB heterooctamer (3B07) and the $\alpha$-toxin heptamer (7AHL). Refinement was carried out in Refmac5 (Murshudov et al., 1997), alternating with manual rebuilding and adjustment in COOT (Emsley and Cowtan, 2004). Coordinates for the $\mathrm{C}_{14} \mathrm{PC}$ molecule were generated using LibCheck (Vagin et al., 2004). TLS refinement was performed in Refmac5 (Winn et al., 2001). Detailed collection and refinement statistics are summarized in Table 1.

\section{Structural Analyses}

Model quality was judged using the programs Rampage, Procheck and Sfcheck (Laskowski et al., 1993; Lovell et al., 2003; Vaguine et al., 1999). Protein-ligand contacts for the toxin- $\mathrm{C}_{14} \mathrm{PC}$ complex structures were analyzed using the program COOT (Emsley et al., 2010). The rmsd values were calculated using the program SuperPose (Maiti et al., 2004). Molecular and solventaccessible surfaces were calculated with the AREAIMOL program (Lee and Richards, 1971) from the CCP4 suite (Winn et al., 2011). PyMOL (DeLano Scientific) was used to render structure figures.

\section{Differential Scanning Calorimetry}

Protein thermal stability was determined by differential scanning calorimetry (DSC) using a NanoDSC model 602000 calorimeter (TA instruments). Protein solutions in buffer A (20 mM sodium acetate [pH 5.8], $50 \mathrm{mM} \mathrm{NaCl}$ ) in the presence and absence of $4 \mathrm{mM}$ PCho were subjected to a temperature increase of $1^{\circ} \mathrm{C} / \mathrm{min}$ from $0^{\circ} \mathrm{C}$ to $100^{\circ} \mathrm{C}$ under a pressure of $3 \mathrm{~atm}$, and the evolution of heat was recorded as a differential power between reference (buffer A) and sample $(10 \mu \mathrm{M}$ protein in buffer A) cells. The resulting thermograms (after buffer subtraction) were used to derive thermal transition midpoints ( $\mathrm{T}_{\mathrm{m}}$ 's). Fitting to the two-state scaled model provided in NanoAnalyze software was used to obtain a $T_{m}$ value. The experiments were repeated two times with consistent results.

\section{Isolation of Human Peripheral Blood Mononuclear Cells (PBMCs)}


Blood samples were obtained from healthy, consenting donors as Buffy coats (New York Blood Center) and leukopaks (AllCells, Alameda, CA). PBMCs were isolated from peripheral blood by density gradient centrifugation using Ficoll-Paque Plus (GE life sciences).

\section{Cytolysis Inhibition Assay}

Flow cytometry was used to assay permeabilization of the plasma membrane (pore formation) by LukED, PVL and $\alpha$-toxin in Jurkat cells and primary human immune cells as described previously (Alonzo et al., 2012). Briefly, serial dilutions of $\mathrm{C}_{14} \mathrm{PC}$ were preincubated individually with different concentrations of the LukD and LukF-PV F subunits and $\alpha$-toxin in V-bottom 96 wellplate for $30 \mathrm{~min}$ at $4^{\circ} \mathrm{C}$. These mixtures were then added to prestained PBMCs and incubated with the cognate LukE and LukS-PV S partners for $1-1.5 \mathrm{~h}$ and with $\alpha$-toxin for $24 \mathrm{~h}$ in a humidified $5 \% \mathrm{CO}_{2}$ incubator at $37^{\circ} \mathrm{C}$. The cytotoxin-treated cells were stained with a viability dye and analyzed by FACS. 50\% inhibitory concentration $\left(\mathrm{IC}_{50}\right)$ values are calculated using GraphPad Prism by fitting data to single-slope dose-response curves constrained to $0 \%$ and $100 \%$ values.

\section{Staining and FACS Analysis}

PBMCs were differentially stained with specific cell surface markers prior to intoxication in order to identify distinct cell populations. Antibodies used for flow cytometric staining included CD3Alexa 532 (clone UCHT1) (eBioscience, San Diego, CA), CD4-Brilliant Violet 570, CD8-Pacific Blue, CD45RO-APCCy7, CD14-Alexa 700, CD27-PeCy7, CD244 (2B4)-Percp Cy5.5, CXCR1APC (Biolegend, San Diego, CA), CCR5-PE (BD Biosciences, San Diego, CA) and CCR7-FITC (R\&D systems, Minneapolis, MN). After intoxication, cells were collected, washed with phosphate buffered saline and stained with Fixable viability dye eFluor 506 (eBioscience, San Diego, CA). Data were acquired on BD LSRFortessa X-20 instrument (BD Biosciences, CA) using FACSDiva software, iQue Screener PLUS (Intellicyt, MI) using ForeCyt Software or SP6800 Spectral Analyzer (Sony Biotechnology, CA). Data analysis was performed using FlowJo software (TreeStar Inc, Ashland, OR). Statistical analysis was performed using GraphPad Prism 8 software.

\section{Accession Numbers}

Coordinates and structure factors have been deposited in the Protein Data Bank with accession codes $6 \mathrm{U} 33$ (LukD), 6U2S (LukD $\left.+\mathrm{C}_{14} \mathrm{PC}\right), 6 \mathrm{U} 3 \mathrm{~F}\left(\mathrm{LukF}-\mathrm{PV}+\mathrm{C}_{14} \mathrm{PC}\right), 6 \mathrm{U} 3 \mathrm{~T}\left(\alpha\right.$-toxin ${ }^{\mathrm{H} 35 \mathrm{~A}}+$ 
$\mathrm{C}_{14} \mathrm{PC}$ ), $6 \mathrm{U} 3 \mathrm{Y}$ (the PVL heterooctamer $+\mathrm{C}_{14} \mathrm{PC}$ ), $6 \mathrm{U} 49$ (the $\alpha$-toxin heptamer $+\mathrm{C}_{14} \mathrm{PC}$ ) and 6U4P (the $\alpha$-toxin ${ }_{\mathrm{H} 35 \mathrm{~A}}$ heptamer $+\mathrm{C}_{14} \mathrm{PC}$ ).

\section{Acknowledgments}

We thank the beamline personnel at the Cornell High Energy Synchrotron Source and the Stanford Synchrotron Radiation Lightsource for data collection, J. Cai for her participation and assistance in the early stage of the project, M. Zhang and Q. Li for technical assistance, and J. Nunberg, N. Kallenbach and J. Lu for comments on the manuscript. This research was supported by NIH grant AI094599.

\section{Author Contributions}

J.L. and M.L. performed the biochemical and biophysical experiments and the co-structure determinations. L.K. and D.U. performed the toxin activity and inhibition measurements. M.L. and D.U. wrote the manuscript with contributions from the other authors. M.L., D.U. and V.T. initiated the project.

\section{Declaration of Interests}

The authors declare no competing interests. 


\section{Figure Legends}

\section{Figure 1. Structural Basis for $\mathrm{C}_{14} \mathrm{PC}$ Binding to $\mathrm{LukD}$}

(A) Cocrystal structure of $\mathrm{C}_{14} \mathrm{PC}$ bound to LukD shown from side view perpendicular to the membrane plane, with the PCho moieties and the side chains of key binding site residues displayed as CPK spheres and in ball-and-stick format, respectively. The amino latch (magenta) and prestem (yellow) regions and the $\beta$-sandwich (green) and rim (blue) domains are indicated. The two binding sites are labeled, as are the $\beta$-strands that compose the rim domain and the $\Omega 1$ and $\Omega 2$ loops.

(B) $2 \mathrm{~F}_{\mathrm{o}}-\mathrm{F}_{\mathrm{c}}$ omit electron density maps (green mesh) for the two PCho moieties at $1.5 \sigma$ contour level.

(C) Surface representation of the $\mathrm{C}_{14} \mathrm{PC}-\mathrm{LukD}$ complex viewed parallel to the membrane, with the PCho moieties shown in stick format with transparent CPK spheres. The locations of key binding site residues are indicated.

(D) Close-up view of the two adjacent PCho binding pockets, with residues that make direct side chain contacts with the PCho moieties shown in ball-and-stick format. Cation- $\pi$ interactions are represented as green dotted lines. Hydrogen bonds and salt bridges are shown as pink dotted lines, and water molecules as purple spheres.

(E) DSC thermograms of LukD in the absence $\left(\mathrm{T}_{\mathrm{m}}=51.0^{\circ} \mathrm{C}\right)$ and presence $\left(\mathrm{T}_{\mathrm{m}}=52.8^{\circ} \mathrm{C}\right)$ of PCho.

\section{Figure 2. Structure of $\mathrm{C}_{14} \mathrm{PC}-\mathrm{Bound} \mathrm{Luk}-\mathrm{PV}$}

(A) $2 \mathrm{~F}_{\mathrm{o}}-\mathrm{F}_{\mathrm{c}}$ electron density maps shown as green mesh around the two PCho moieties contoured at $1.5 \sigma$ (site 1$)$ and $1.0 \sigma$ (site 2$)$.

(B) Molecular interactions in the $\mathrm{C}_{14} \mathrm{PC}-\mathrm{LukF}-\mathrm{PV}$ complex, with the PCho moieties shown in stick format with transparent CPK spheres. The side chains of residues that make direct contacts with the PCho moieties are shown in ball-and-stick format. The two binding sites and the $\Omega 1$ and $\Omega 2$ loops are labeled. Cation $-\pi$ interactions are represented as green dotted lines. Hydrogen bonds and salt bridges are shown as pink dotted lines.

(C) Sequence alignment for members of the $\alpha$-hemolysin pore-forming toxin subfamily around the regions of the three PCho binding sites (see text for details). Four segments of the rim domain (residues 71-75, 170-180, 191-202 and 255-264) and two segments of the stem domain (109117 and 137-145) are delineated by spaces and numbered according to the mature LukF-PV 
protein. Conserved residues at the two binding sites on the rim domain are highlighted red. Conserved residues that constitute the interprotomer binding sites on the PVL heterooctamer and the $\alpha$-toxin heptamer are highlighted green and a yellow background, respectively.

\section{Figure 3. The Two Adjacent PC Binding Pockets on Monomeric $\alpha$-Toxin ${ }^{\mathrm{H} 35 \mathrm{~A}}$}

(A) $2 F_{o}-F_{c}$ electron density maps (green mesh) for the two PCho moieties contoured at $1.2 \sigma$ (site 1) and $1.0 \sigma$ (site 2$)$.

(B) Surface representation of the $\mathrm{C}_{14} \mathrm{PC}-\alpha$-toxin ${ }^{\mathrm{H} 35 \mathrm{~A}}$ complex viewed parallel to the membrane, with the PCho moieties shown in stick format with transparent CPK spheres. The two binding sites are labeled. The locations of key binding site residues are indicated.

(C) Close-up view of the two adjacent PCho binding pockets, with the PCho moieties displayed in stick format with transparent CPK spheres. Residues that make direct side chain contacts with the PCho moieties are shown in ball-and-stick format. The $\Omega 1$ and $\Omega 2$ loops are labeled. Cation $-\pi$ interactions are represented as green dotted lines. Hydrogen bonds are shown as pink dotted lines. (D) Close-up view of the interface between the two independent $\alpha$-toxin ${ }^{\mathrm{H} 35 \mathrm{~A}}$ monomers (blue and green, respectively) in the asymmetric unit. Hydrogen bonds and salt bridges near the His35 $\rightarrow$ Ala mutation site are depicted as pink dotted lines.

\section{Figure 4. Crystal Structure of $\mathrm{C}_{14} \mathrm{PC}$ in Complex with the PVL Heterooctamer}

(A, B) Ribbon representation of the $\mathrm{C}_{14} \mathrm{PC}$-bound PVL heterooctamer shown from the side (A) and cytoplasmic (B) views, with the PCho moieties and the side chain of Trp176 displayed as CPK spheres and in stick format, respectively. The LukF-PV and LukS-PV subunits are colored green and yellow, respectively. The $\beta$-sandwich, rim and stem domains are indicated.

(C) $2 \mathrm{~F}_{\mathrm{o}}-\mathrm{F}_{\mathrm{c}}$ omit electron density maps contoured at 1.0 shown as green mesh around the three PCho moieties in a single protomeric unit.

(D) Surface representation of the three PCho binding pockets on a single protomeric unit viewed from the cytoplasmic side, with the PCho moieties shown in stick format with transparent CPK spheres. The three binding sites are labeled. The locations of key binding site residues are indicated. (E) Close-up view of the PCho moieties in the three binding pockets on a single protomeric unit. The side chains of residues that make direct contacts with the PCho moieties are shown in balland-stick format colored in blue for protomer A, in magenta for protomer $\mathrm{G}$ and in yellow for 
protomer $H$. The $\Omega 1$ and $\Omega 2$ loops are labeled. Cation $-\pi$ interactions are depicted as green dotted lines. Hydrogen bonds and salt bridges are represented as pink dotted lines.

\section{Figure 5. Structure of $\mathrm{C}_{14} \mathrm{PC}$ Bound to the $\alpha$-Toxin Heptamer}

(A, B) Ribbon representation of $\mathrm{C}_{14} \mathrm{PC}$ in complex with $\alpha$-toxin heptamer shown from the side (A) and cytoplasmic (B) views, with the PCho moieties and the side chain of Trp179 displayed as CPK spheres and in stick format, respectively. The amino latch region and the $\beta$-sandwich, rim and stem domains are colored as in Figure 1A.

(C) A $2 \mathrm{~F}_{\mathrm{o}}-\mathrm{F}_{\mathrm{c}}$ electron density map (green mesh) contoured at $1.0 \sigma$ for residues Asn178, Trp179 and Gly180 and the three PCho moieties in a single protomeric unit.

(D) Surface representation of the three partially overlapping PCho binding pockets on a single protomeric unit viewed from the cytoplasmic side, with the PCho moieties shown in stick format with transparent CPK spheres. The three binding pockets are labeled. The locations of key binding site residues are indicated.

(E) Molecular interactions in the heptameric $\alpha$-toxin- $\mathrm{C}_{14} \mathrm{PC}$ complex, with the PCho moieties in a single protomeric unit displayed in ball-to-stick format. Residues that make direct side chain contacts with the PCho moieties are shown in ball-and-stick format colored in blue for protomer A, in purple for protomer $\mathrm{E}$ and in yellow for protomer F. The $\Omega 1$ and $\Omega 2$ loops are labeled. Cation- $\pi$ interactions are represented as green dotted lines. Hydrogen bonds and salt bridges are shown as pink dotted lines.

(F) Close-up view of interprotomer interactions in the triangle region in the crystal structure of the $\mathrm{C}_{14} \mathrm{PC}$ bound $\alpha$-toxin ${ }^{\mathrm{H} 35 \mathrm{~A}}$ heptamer. Protomers $\mathrm{A}, \mathrm{B}$ and $\mathrm{C}$ are colored blue, green and yellow, respectively.

\section{Figure 6. $\mathrm{C}_{14} \mathrm{PC}$ Protects Target Cells from LukED-Mediated Cytolysis}

(A) Titration of LukED cytotoxicity by $\mathrm{C}_{14} \mathrm{PC}$. $\mathrm{CCR} 5^{+}$Jurkat cells were challenged with different concentrations of LukED in the presence and absence of $\mathrm{C}_{14} \mathrm{PC}$. Cell viability was determined by flow cytometry. Data are representative of at least three independent experiments and values are expressed in the mean of triplicate measurements \pm standard error (SE).

(B) Protective effect of $\mathrm{C}_{14} \mathrm{PC}$ against LukED killing of primary human monocytes. PBMCs were challenged with LukED in the presence and absence of $\mathrm{C}_{14} \mathrm{PC}$. Monocyte subsets were identified 
as $\mathrm{CD}^{-}{ }^{-} \mathrm{CD} 14^{+}$after gating on live PBMCs as determined by flow cytometry. Data are representative of two independent experiments. Percentages of cells in each quadrant are indicated. (C) Protective effect of $\mathrm{C}_{14} \mathrm{PC}$ against LukED killing of $\mathrm{CD}^{+}$effector memory $\mathrm{T}$ cells (CCR7$\mathrm{CD}^{2} 4 \mathrm{RO}^{+}$and $\mathrm{CCR}^{-} \mathrm{CD}^{-} \mathrm{RO}^{-}$). PBMCs were challenged with LukED in the presence and absence of $\mathrm{C}_{14} \mathrm{PC}$. Live $\mathrm{CD}^{+} \mathrm{CD}^{+} \mathrm{T}$ cell subsets were gated and analyzed for the expression of CCR7 and CD45RO by flow cytometry. Data are representative of two independent experiments using blood from different donors.

(D) Bar graph showing the inhibition of LukED-mediated cytolysis of monocytes after pretreatment with $\mathrm{C}_{14} \mathrm{PC}$. Error bars indicate SEM.

(E) Bar graph showing $\mathrm{C}_{14} \mathrm{PC}$ inhibition of LukED-induced lysis of $\mathrm{CD}^{+}$effector memory $\mathrm{T}$ cells. Error bars indicate SEM.

(F) Protective effect of $\mathrm{C}_{14} \mathrm{PC}$ against LukED killing of $\mathrm{CD}^{+} \mathrm{CCR} 5^{+} \mathrm{T}$ cells. PBMCs were challenged with LukED in the presence and absence of $\mathrm{C}_{14} \mathrm{PC}$. Live $\mathrm{CD}^{+} \mathrm{CD}^{+} \mathrm{T}$ cell subsets were gated and analyzed for the expression of CCR5 and CD45RO by flow cytometry. Data are representative of two independent experiments.

(G) Protective effect of $\mathrm{C}_{14} \mathrm{PC}$ against LukED killing of NK cells. PBMCs were challenged with LukED in the presence and absence of $\mathrm{C}_{14} \mathrm{PC}$. PBMCs were first gated on live $\mathrm{CD}^{-}{ }^{-} \mathrm{HLA}^{-} \mathrm{DR}^{-}$ cells and proportion of $\mathrm{CXCR} 1^{+} 2 \mathrm{~B} 4^{+} \mathrm{NK}$ cells was analyzed by flow cytometry. Data are representative of two independent experiments.

\section{Figure 7. Protection of Primary Human Monocytes Against PVL and $\alpha$-Toxin by $\mathrm{C}_{14} \mathrm{PC}$}

(A) Protective effect of $\mathrm{C}_{14} \mathrm{PC}$ against PVL killing of monocytes. PBMCs were challenged with PVL in the presence and absence of $\mathrm{C}_{14} \mathrm{PC}$. Monocyte subsets were gated based on the FSC and SSC parameters and then analyzed for the expression of $\mathrm{CD}_{14}{ }^{+}$and $\mathrm{CD}^{+}$, respectively. Cell viability was determined by flow cytometry and normalized to that in the medium control. Data are representative of two independent experiments using blood from different donors. Percentages of cells in each quadrant are indicated.

(B) Bar graph showing the protection from PVL-mediated cytolysis of monocytes by $\mathrm{C}_{14} \mathrm{PC}$. Error bars indicate SEM.

(C) Protective effect of $\mathrm{C}_{14} \mathrm{PC}$ against $\alpha$-toxin-mediated killing of monocytes. PBMCs were challenged with $\alpha$-toxin in the presence and absence of $\mathrm{C}_{14} \mathrm{PC}$. Monocyte subsets were identified 
and quantified as described in A. Data are representative of two independent experiments using blood from different donors.

(D) Bar graph showing the inhibition of $\alpha$-toxin-induced lysis of monocytes by $\mathrm{C}_{14} \mathrm{PC}$. Error bars indicate SEM. 


\section{References}

Alonzo, F., 3rd, Benson, M.A., Chen, J., Novick, R.P., Shopsin, B., and Torres, V.J. (2012). Staphylococcus aureus leucocidin ED contributes to systemic infection by targeting neutrophils and promoting bacterial growth in vivo. Mol. Microbiol. 83, 423-435.

Alonzo, F., 3rd, Kozhaya, L., Rawlings, S.A., Reyes-Robles, T., DuMont, A.L., Myszka, D.G., Landau, N.R., Unutmaz, D., and Torres, V.J. (2013). CCR5 is a receptor for Staphylococcus aureus leukotoxin ED. Nature 493, 51-55.

Alonzo, F., 3rd, and Torres, V.J. (2014). The bicomponent pore-forming leucocidins of Staphylococcus aureus. MMBR 78, 199-230.

Anderson, M.J., Schaaf, E., Breshears, L.M., Wallis, H.W., Johnson, J.R., Tkaczyk, C., Sellman, B.R., Sun, J., and Peterson, M.L. (2018). Alpha-toxin contributes to biofilm formation among Staphylococcus aureus wound isolates. Toxins 10, 157.

Badarau, A., Rouha, H., Malafa, S., Logan, D.T., Hakansson, M., Stulik, L., Dolezilkova, I., Teubenbacher, A., Gross, K., Maierhofer, B., et al. (2015). Structure-function analysis of heterodimer formation, oligomerization, and receptor binding of the Staphylococcus aureus bicomponent toxin LukGH. J. Biol. Chem. 290, 142-156.

Berube, B.J., and Bubeck Wardenburg, J. (2013). Staphylococcus aureus alpha-toxin: nearly a century of intrigue. Toxins 5, 1140-1166.

Bhattacharya, M., Berends, E.T.M., Chan, R., Schwab, E., Roy, S., Sen, C.K., Torres, V.J., and Wozniak, D.J. (2018). Staphylococcus aureus biofilms release leukocidins to elicit extracellular trap formation and evade neutrophil-mediated killing. Proc. Natl. Acad. Sci. USA 115, 7416-7421. Bowler, P.G. (2018). Antibiotic resistance and biofilm tolerance: a combined threat in the treatment of chronic infections. J. Wound Care 27, 273-277.

Bubeck Wardenburg, J., and Schneewind, O. (2008). Vaccine protection against Staphylococcus aureus pneumonia. J. Exp. Med. 205, 287-294.

Chambers, H.F., and Deleo, F.R. (2009). Waves of resistance: Staphylococcus aureus in the antibiotic era. Nat. Rev. Microbiol. 7, 629-641.

Courvalin, P. (2006). Vancomycin resistance in gram-positive cocci. Clin. Infect. Dis. 42 Suppl 1, S25-34.

Dal Peraro, M., and van der Goot, F.G. (2016). Pore-forming toxins: ancient, but never really out of fashion. Nat. Rev. Microbiol. 14, 77-92.

DeLeo, F.R., Kennedy, A.D., Chen, L., Bubeck Wardenburg, J., Kobayashi, S.D., Mathema, B., Braughton, K.R., Whitney, A.R., Villaruz, A.E., Martens, C.A., et al. (2011). Molecular differentiation of historic phage-type 80/81 and contemporary epidemic Staphylococcus aureus. Proc. Natl. Acad. Sci. USA 108, 18091-18096. 
Diekema, D.J., Richter, S.S., Heilmann, K.P., Dohrn, C.L., Riahi, F., Tendolkar, S., McDanel, J.S., and Doern, G.V. (2014). Continued emergence of USA300 methicillin-resistant Staphylococcus aureus in the United States: results from a nationwide surveillance study. Infect. Control Hosp. Epidemiol. 35, 285-292.

Diep, B.A., Chan, L., Tattevin, P., Kajikawa, O., Martin, T.R., Basuino, L., Mai, T.T., Marbach, H., Braughton, K.R., Whitney, A.R., et al. (2010). Polymorphonuclear leukocytes mediate Staphylococcus aureus Panton-Valentine leukocidin-induced lung inflammation and injury. Proc. Natl. Acad. Sci. USA 107, 5587-5592.

Diep, B.A., Gill, S.R., Chang, R.F., Phan, T.H., Chen, J.H., Davidson, M.G., Lin, F., Lin, J., Carleton, H.A., Mongodin, E.F., et al. (2006). Complete genome sequence of USA300, an epidemic clone of community-acquired meticillin-resistant Staphylococcus aureus. Lancet 367, 731-739.

Dorlo, T.P., Balasegaram, M., Beijnen, J.H., and de Vries, P.J. (2012). Miltefosine: a review of its pharmacology and therapeutic efficacy in the treatment of leishmaniasis. J. Antimicrob. Chemother. 67, 2576-2597.

DuMont, A.L., Yoong, P., Liu, X., Day, C.J., Chumbler, N.M., James, D.B., Alonzo, F., 3rd, Bode, N.J., Lacy, D.B., Jennings, M.P., et al. (2014). Identification of a crucial residue required for Staphylococcus aureus LukAB cytotoxicity and receptor recognition. Infect. Immun. 82, 12681276.

Emsley, P., and Cowtan, K. (2004). Coot: model-building tools for molecular graphics. Acta Cryst. D 60, 2126-2132.

Emsley, P., Lohkamp, B., Scott, W.G., and Cowtan, K. (2010). Features and development of Coot. Acta Cryst. D 66, 486-501.

Ferreras, M., Hoper, F., Dalla Serra, M., Colin, D.A., Prevost, G., and Menestrina, G. (1998). The interaction of Staphylococcus aureus bi-component gamma-hemolysins and leucocidins with cells and lipid membranes. Biochim. Biophys. Acta 1414, 108-126.

Galdiero, S., and Gouaux, E. (2004). High resolution crystallographic studies of alpha-hemolysinphospholipid complexes define heptamer-lipid head group interactions: implication for understanding protein-lipid interactions. Protein Sci. 13, 1503-1511.

Gardete, S., and Tomasz, A. (2014). Mechanisms of vancomycin resistance in Staphylococcus aureus. J. Clin. Invest. 124, 2836-2840.

Gauduchon, V., Werner, S., Prevost, G., Monteil, H., and Colin, D.A. (2001). Flow cytometric determination of Panton-Valentine leucocidin S component binding. Infect. Immun. 69, 23902395. 
Gillet, Y., Issartel, B., Vanhems, P., Fournet, J.C., Lina, G., Bes, M., Vandenesch, F., Piemont, Y., Brousse, N., Floret, D., et al. (2002). Association between Staphylococcus aureus strains carrying gene for Panton-Valentine leukocidin and highly lethal necrotising pneumonia in young immunocompetent patients. Lancet 359, 753-759.

Gouaux, E., Hobaugh, M., and Song, L. (1997). alpha-Hemolysin, gamma-hemolysin, and leukocidin from Staphylococcus aureus: distant in sequence but similar in structure. Protein Sci. 6, 2631-2635.

Guillet, V., Roblin, P., Werner, S., Coraiola, M., Menestrina, G., Monteil, H., Prevost, G., and Mourey, L. (2004). Crystal structure of leucotoxin S component: new insight into the Staphylococcal beta-barrel pore-forming toxins. J. Biol. Chem. 279, 41028-41037.

Hua, L., Cohen, T.S., Shi, Y., Datta, V., Hilliard, J.J., Tkaczyk, C., Suzich, J., Stover, C.K., and Sellman, B.R. (2015). MEDI4893* Promotes Survival and Extends the Antibiotic Treatment Window in a Staphylococcus aureus Immunocompromised Pneumonia Model. Antimicrob. Agents Chemother. 59, 4526-4532.

Jones, S.M., Morgan, M., Humphrey, T.J., and Lappin-Scott, H. (2001). Effect of vancomycin and rifampicin on meticillin-resistant Staphylococcus aureus biofilms. Lancet 357, 40-41.

Jursch, R., Hildebrand, A., Hobom, G., Tranum-Jensen, J., Ward, R., Kehoe, M., and Bhakdi, S. (1994). Histidine residues near the $\mathrm{N}$ terminus of staphylococcal alpha-toxin as reporters of regions that are critical for oligomerization and pore formation. Infect. Immun. 62, 2249-2256.

Kawate, T., and Gouaux, E. (2003). Arresting and releasing Staphylococcal alpha-hemolysin at intermediate stages of pore formation by engineered disulfide bonds. Protein Sci. 12, 997-1006.

Klevens, R.M., Morrison, M.A., Nadle, J., Petit, S., Gershman, K., Ray, S., Harrison, L.H., Lynfield, R., Dumyati, G., Townes, J.M., et al. (2007). Invasive methicillin-resistant Staphylococcus aureus infections in the United States. JAMA 298, 1763-1771.

Krishnasastry, M., Walker, B., Braha, O., and Bayley, H. (1994). Surface labeling of key residues during assembly of the transmembrane pore formed by staphylococcal alpha-hemolysin. FEBS Lett. 356, 66-71.

Laskowski, R.A., MacArthur, M.W., Moss, D.S., and Thornton, J.M. (1993). PROCHECK: a program to check the stereochemical quality of protein structures. J. Appl. Crystallogr. 26, 283291.

Le, V.T., Tkaczyk, C., Chau, S., Rao, R.L., Dip, E.C., Pereira-Franchi, E.P., Cheng, L., Lee, S., Koelkebeck, H., Hilliard, J.J., et al. (2016). Critical Role of Alpha-Toxin and Protective Effects of Its Neutralization by a Human Antibody in Acute Bacterial Skin and Skin Structure Infections. Antimicrob. Agents Chemother. 60, 5640-5648. 
Lee, B., and Richards, F.M. (1971). The interpretation of protein structures: estimation of static accessibility. J. Mol. Biol. 55, 379-400.

Liang, X., Yan, M., and Ji, Y. (2009). The H35A mutated alpha-toxin interferes with cytotoxicity of staphylococcal alpha-toxin. Infect. Immun. 77, 977-983.

Lina, G., Piemont, Y., Godail-Gamot, F., Bes, M., Peter, M.O., Gauduchon, V., Vandenesch, F., and Etienne, J. (1999). Involvement of Panton-Valentine leukocidin-producing Staphylococcus aureus in primary skin infections and pneumonia. Clin. Infect. Dis. 29, 1128-1132.

Liu, C., Bayer, A., Cosgrove, S.E., Daum, R.S., Fridkin, S.K., Gorwitz, R.J., Kaplan, S.L., Karchmer, A.W., Levine, D.P., Murray, B.E., et al. (2011). Clinical practice guidelines by the infectious diseases society of america for the treatment of methicillin-resistant Staphylococcus aureus infections in adults and children: executive summary. Clin. Infect. Dis. 52, 285-292.

Loffler, B., Hussain, M., Grundmeier, M., Bruck, M., Holzinger, D., Varga, G., Roth, J., Kahl, B.C., Proctor, R.A., and Peters, G. (2010). Staphylococcus aureus panton-valentine leukocidin is a very potent cytotoxic factor for human neutrophils. PLoS Pathog. 6, e1000715.

Lovell, S.C., Davis, I.W., Arendall, W.B., 3rd, de Bakker, P.I., Word, J.M., Prisant, M.G., Richardson, J.S., and Richardson, D.C. (2003). Structure validation by Calpha geometry: phi,psi and Cbeta deviation. Proteins 50,437-450.

Lowy, F.D. (1998). Staphylococcus aureus infections. N. Engl. J. Med. 339, 520-532.

Maiti, R., Van Domselaar, G.H., Zhang, H., and Wishart, D.S. (2004). SuperPose: a simple server for sophisticated structural superposition. Nucleic Acids Res. 32, W590-594.

McCoy, A.J., Grosse-Kunstleve, R.W., Adams, P.D., Winn, M.D., Storoni, L.C., and Read, R.J. (2007). Phaser crystallographic software. J. Appl. Crystallogr. 40, 658-674.

Menzies, B.E., and Kernodle, D.S. (1994). Site-directed mutagenesis of the alpha-toxin gene of Staphylococcus aureus: role of histidines in toxin activity in vitro and in a murine model. Infect. Immun. 62, 1843-1847.

Monma, N., Nguyen, V.T., Kaneko, J., Higuchi, H., and Kamio, Y. (2004). Essential residues, W177 and R198, of LukF for phosphatidylcholine-binding and pore-formation by staphylococcal gamma-hemolysin on human erythrocyte membranes. J. Biochem. 136, 427-431.

Murshudov, G.N., Vagin, A.A., and Dodson, E.J. (1997). Refinement of macromolecular structures by the maximum-likehood method. Acta Cryst. D 53, 240-255.

Nagle, J.F., and Tristram-Nagle, S. (2000). Lipid bilayer structure. Curr. Opin. Struct. Biol. 10, 474-480. 
Nocadello, S., Minasov, G., Shuvalova, L., Dubrovska, I., Sabini, E., Bagnoli, F., Grandi, G., and Anderson, W.F. (2016). Crystal structures of the components of the Staphylococcus aureus leukotoxin ED. Acta Cryst. D 72, 113-120.

Noda, M., Kato, I., Hirayama, T., and Matsuda, F. (1980). Fixation and inactivation of staphylococcal leukocidin by phosphatidylcholine and ganglioside GM1 in rabbit polymorphonuclear leukocytes. Infect. Immun. 29, 678-684.

Olson, R., Nariya, H., Yokota, K., Kamio, Y., and Gouaux, E. (1999). Crystal structure of staphylococcal LukF delineates conformational changes accompanying formation of a transmembrane channel. Nat. Struct. Biol. 6, 134-140.

Otto, M. (2008). Staphylococcal biofilms. Curr. Top. Microbiol. Immunol. 322, 207-228.

Otto, M. (2010). Basis of virulence in community-associated methicillin-resistant Staphylococcus aureus. Annu. Rev. Microbiol. 64, 143-162.

Otwinowski, Z., and Minor, W. (1997). Processing of X-ray diffraction data collected in oscillation mode. Methods Enzymol. 276, 307-326.

Pedelacq, J.D., Maveyraud, L., Prevost, G., Baba-Moussa, L., Gonzalez, A., Courcelle, E., Shepard, W., Monteil, H., Samama, J.P., and Mourey, L. (1999). The structure of a Staphylococcus aureus leucocidin component (LukF-PV) reveals the fold of the water-soluble species of a family of transmembrane pore-forming toxins. Structure 7, 277-287.

Potrich, C., Bastiani, H., Colin, D.A., Huck, S., Prevost, G., and Dalla Serra, M. (2009). The influence of membrane lipids in Staphylococcus aureus gamma-hemolysins pore formation. J. Membr. Biol. 227, 13-24.

Reyes-Robles, T., Alonzo, F., 3rd, Kozhaya, L., Lacy, D.B., Unutmaz, D., and Torres, V.J. (2013). Staphylococcus aureus leukotoxin ED targets the chemokine receptors CXCR1 and CXCR2 to kill leukocytes and promote infection. Cell Host Microbe. 14, 453-459.

Sause, W.E., Buckley, P.T., Strohl, W.R., Lynch, A.S., and Torres, V.J. (2016). Antibody-Based Biologics and Their Promise to Combat Staphylococcus aureus Infections. Trends Pharmacol. Sci. $37,231-241$.

Song, L., Hobaugh, M.R., Shustak, C., Cheley, S., Bayley, H., and Gouaux, J.E. (1996). Structure of staphylococcal alpha-hemolysin, a heptameric transmembrane pore. Science 274, 1859-1866.

Spaan, A.N., Henry, T., van Rooijen, W.J., Perret, M., Badiou, C., Aerts, P.C., Kemmink, J., de Haas, C.J., van Kessel, K.P., Vandenesch, F., et al. (2013). The staphylococcal toxin PantonValentine Leukocidin targets human C5a receptors. Cell Host Microbe. 13, 584-594.

Spaan, A.N., van Strijp, J.A.G., and Torres, V.J. (2017). Leukocidins: staphylococcal bicomponent pore-forming toxins find their receptors. Nat. Rev. Microbiol. 15, 435-447. 
Sugawara, T., Yamashita, D., Kato, K., Peng, Z., Ueda, J., Kaneko, J., Kamio, Y., Tanaka, Y., and Yao, M. (2015). Structural basis for pore-forming mechanism of staphylococcal alpha-hemolysin. Toxicon 108, 226-231.

Vagin, A.A., Steiner, R.A., Lebedev, A.A., Potterton, L., McNicholas, S., Long, F., and Murshudov, G.N. (2004). REFMAC5 dictionary: organization of prior chemical knowledge and guidelines for its use. Acta Cryst. D 60, 2184-2195.

Vaguine, A.A., Richelle, J., and Wodak, S.J. (1999). SFCHECK: a unified set of procedures for evaluating the quality of macromolecular structure-factor data and their agreement with the atomic model. Acta Cryst. D 55, 191-205.

Valeva, A., Hellmann, N., Walev, I., Strand, D., Plate, M., Boukhallouk, F., Brack, A., Hanada, K., Decker, H., and Bhakdi, S. (2006). Evidence that clustered phosphocholine head groups serve as sites for binding and assembly of an oligomeric protein pore. J. Biol. Chem. 281, 26014-26021.

Valeva, A., Pongs, J., Bhakdi, S., and Palmer, M. (1997). Staphylococcal alpha-toxin: the role of the N-terminus in formation of the heptameric pore -- a fluorescence study. Biochim. Biophys. Acta 1325, 281-286.

Walker, B., and Bayley, H. (1995). Key residues for membrane binding, oligomerization, and pore forming activity of staphylococcal alpha-hemolysin identified by cysteine scanning mutagenesis and targeted chemical modification. J. Biol. Chem. 270, 23065-23071.

Ward, P.D., and Turner, W.H. (1980). Identification of staphylococcal Panton-Valentine leukocidin as a potent dermonecrotic toxin. Infect. Immun. 28, 393-397.

Watanabe, M., Tomita, T., and Yasuda, T. (1987). Membrane-damaging action of staphylococcal alpha-toxin on phospholipid-cholesterol liposomes. Biochim. Biophys. Acta 898, 257-265.

Wilke, G.A., and Bubeck Wardenburg, J. (2010). Role of a disintegrin and metalloprotease 10 in Staphylococcus aureus alpha-hemolysin-mediated cellular injury. Proc. Natl. Acad. Sci. USA 107, 13473-13478.

Willyard, C. (2017). The drug-resistant bacteria that pose the greatest health threats. Nature 543, 15.

Winn, M.D., Ballard, C.C., Cowtan, K.D., Dodson, E.J., Emsley, P., Evans, P.R., Keegan, R.M., Krissinel, E.B., Leslie, A.G., McCoy, A., et al. (2011). Overview of the CCP4 suite and current developments. Acta Cryst. D 67, 235-242.

Winn, M.D., Isupov, M.N., and Murshudov, G.N. (2001). Use of TLS parameters to model anisotropic displacements in macromolecular refinement. Acta Cryst. D 57, 122-133. 
Woodin, A.M. (1960). Purification of the two components of leucocidin from Staphylococcus aureus. Biochem. J. 75, 158-165.

Yamashita, D., Sugawara, T., Takeshita, M., Kaneko, J., Kamio, Y., Tanaka, I., Tanaka, Y., and Yao, M. (2014). Molecular basis of transmembrane beta-barrel formation of staphylococcal poreforming toxins. Nat. Commun. 5, 4897.

Yamashita, K., Kawai, Y., Tanaka, Y., Hirano, N., Kaneko, J., Tomita, N., Ohta, M., Kamio, Y., Yao, M., and Tanaka, I. (2011). Crystal structure of the octameric pore of staphylococcal gammahemolysin reveals the beta-barrel pore formation mechanism by two components. Proc. Natl. Acad. Sci. USA 108, 17314-17319.

Yokota, K., and Kamio, Y. (2000). Tyrosine72 residue at the bottom of rim domain in LukF crucial for the sequential binding of the staphylococcal gamma-hemolysin to human erythrocytes. Biosci. Biotechnol. Biochem. 64, 2744-2747. 
Table 1. X-Ray Data Collection and Refinement Statistics

\begin{tabular}{|c|c|c|c|c|}
\hline Structure & LukD & $\mathrm{LukD}+\mathrm{C}_{14} \mathrm{PC}$ & LukF-PV + $\mathrm{C}_{14} \mathrm{PC}$ & $\alpha-\operatorname{Toxin}^{\mathrm{H} 35 \mathrm{~A}}+\mathrm{C}_{14} \mathrm{PC}$ \\
\hline \multicolumn{5}{|l|}{ Data collection } \\
\hline Wavelength $(\AA) /$ beam line & $0.979 / \mathrm{NSLS} X 4 \mathrm{C}$ & 0.977/MacCHESS-F1 & 0.979/SSRL 9-2 & 0.979/SSRL 9-2 \\
\hline Space group & $\mathrm{C} 2$ & $\mathrm{C} 2$ & $\mathrm{P} 3221$ & I422 \\
\hline $\mathrm{a}(\AA)$ & 123.61 & 149.20 & 49.25 & 136.18 \\
\hline $\mathrm{b}(\AA)$ & 48.73 & 37.77 & 49.25 & 136.18 \\
\hline $\mathrm{c}(\AA)$ & 66.73 & 77.91 & 266.87 & 166.04 \\
\hline$\alpha(\AA)$ & 90.0 & 90.0 & 90.0 & 90.0 \\
\hline$\beta\left(^{\circ}\right)$ & 120.8 & 119.8 & 90.0 & 90.0 \\
\hline$\gamma\left({ }^{\circ}\right)$ & 90.0 & 90.0 & 120.0 & 90.0 \\
\hline Resolution $(\AA)^{*}$ & $57.3-1.75(1.78-1.75)$ & $67.6-1.50(1.53-1.50)$ & $89.0-1.78(1.82-1.78)$ & $43.8-2.80(2.87-2.80)$ \\
\hline $\mathrm{R}_{\text {meas }}$ & $0.055(0.297)$ & $0.054(0.270)$ & $0.035(0.109)$ & $0.135(0.912)$ \\
\hline $\mathrm{I} / \sigma(\mathrm{I})$ & $15.8(3.7)$ & $9.7(4.4)$ & $18.9(20.5)$ & $5.4(2.4)$ \\
\hline Completeness (\%) & $92.6(58.7)$ & $97.8(84.7)$ & $99.7(98.2)$ & $99.8(99.1)$ \\
\hline Multiplicity & $3.0(2.3)$ & $3.2(3.0)$ & $9.4(9.2)$ & $12.7(10.4)$ \\
\hline $\mathrm{CC}_{1 / 2}(\%)$ & $98.4(93.8)$ & $98.9(96.1)$ & $99.9(99.7)$ & $95.6(71.6)$ \\
\hline Unique reflections & $32,045(1,505)$ & $59,415(3,824)$ & $37,358(2,428)$ & $19,666(1,262)$ \\
\hline \multicolumn{5}{|l|}{ Refinement statistics } \\
\hline Resolution $(\AA)$ & $57.3-1.75(1.79-1.75)$ & $67.6-1.50(1.54-1.50)$ & $89.0-1.78(1.83-1.78)$ & $43.8-2.80(2.86-2.80)$ \\
\hline $\mathrm{R}_{\text {work }}$ & $0.175(0.231)$ & $0.162(0.216)$ & $0.179(0.154)$ & $0.197(0.295)$ \\
\hline$R_{\text {free }}$ & $0.217(0.286)$ & $0.188(0.245)$ & $0.210(0.195)$ & $0.246(0.381)$ \\
\hline Rmsd bond length $(\AA)$ & 0.019 & 0.019 & 0.017 & 0.003 \\
\hline Rmsd bond angle $\left(^{\circ}\right)$ & 1.9 & 1.9 & 2.4 & 1.0 \\
\hline \multicolumn{5}{|l|}{ Average B factor $\left(\AA^{2}\right)$} \\
\hline Protein & 15.2 & 14.3 & 21.5 & 51.4 \\
\hline $\mathrm{C}_{14} \mathrm{PC}$ & - & 26.1 & 51.5 & 113.5 \\
\hline Water & 34.1 & 39.3 & 37.6 & 59.4 \\
\hline Ion & 35.7 & - & 47.8 & 119.5 \\
\hline \multicolumn{5}{|l|}{ Ramachandran plot } \\
\hline Favored (\%) & 95.6 & 95.5 & 95.5 & 94.4 \\
\hline Allowed (\%) & 4.4 & 4.5 & 4.5 & 5.6 \\
\hline Disallowed (\%) & 0 & 0 & 0 & 0 \\
\hline
\end{tabular}


bioRxiv preprint doi: https://doi.org/10.1101/781971; this version posted October 1,2019 . The copyright holder for this preprint (which was not certified by peer review) is the author/funder. All rights reserved. No reuse allowed without permission.

Table 1 (cont.). X-Ray Data Collection and Refinement Statistics

\begin{tabular}{|c|c|c|c|}
\hline Structure & $\mathrm{PVL}$ heterooctamer $+\mathrm{C}_{14} \mathrm{PC}$ & $\alpha$-Toxin heptamer $+\mathrm{C}_{14} \mathrm{PC}$ & $\alpha$-Toxin ${ }^{\mathrm{H} 35 \mathrm{~A}}$ heptamer $+\mathrm{C}_{14} \mathrm{PC}$ \\
\hline \multicolumn{4}{|l|}{ Data collection } \\
\hline Wavelength $(\AA) /$ beam line & 0.979/SSRL 9-2 & 0.886/SSRL 9-2 & $0.979 /$ SSRL 9-2 \\
\hline Space group & I4422 & $\mathrm{C} 2$ & $\mathrm{C} 2$ \\
\hline a $(\AA)$ & 139.10 & 150.37 & 151.17 \\
\hline $\mathrm{b}(\AA)$ & 139.10 & 135.04 & 134.62 \\
\hline c $(\AA)$ & 246.77 & 132.45 & 130.70 \\
\hline$\alpha(\AA)$ & 90.0 & 90.0 & 90.0 \\
\hline$\beta\left(^{\circ}\right)$ & 90.0 & 91.5 & 91.8 \\
\hline$\gamma\left(\left(^{\circ}\right)\right.$ & 90.0 & 90.0 & 90.0 \\
\hline Resolution $(\AA) *$ & $38.7-2.04(2.08-2.04)$ & $132.4-2.35(2.39-2.35)$ & $37.8-2.50(2.56-2.50)$ \\
\hline $\mathrm{R}_{\text {meas }}$ & $0.098(0.981)$ & $0.101(0.548)$ & $0.061(0.515)$ \\
\hline $\mathrm{I} / \sigma(\mathrm{I})$ & $6.6(2.1)$ & $7.2(2.1)$ & $10.2(2.4)$ \\
\hline Completeness $(\%)$ & $99.9(98.7)$ & $94.5(96.6)$ & $96.5(98.1)$ \\
\hline Multiplicity & $12.8(8.9)$ & $2.8(2.8)$ & $3.4(3.4)$ \\
\hline $\mathrm{CC}_{1 / 2}(\%)$ & $95.6(75.4)$ & $92.5(71.5)$ & $96.8(86.4)$ \\
\hline Unique reflections & $76,882(3,741)$ & $103,631(7,554)$ & $87,452(6,406)$ \\
\hline \multicolumn{4}{|l|}{ Refinement statistics } \\
\hline Resolution $(\AA)$ & $38.7-2.04(2.09-2.04)$ & $132.4-2.35(2.41-2.35)$ & $37.8-2.50(2.56-2.50)$ \\
\hline $\mathrm{R}_{\text {work }}$ & $0.182(0.242)$ & $0.194(0.261)$ & $0.212(0.289)$ \\
\hline$R_{\text {free }}$ & $0.225(0.269)$ & $0.239(0.314)$ & $0.249(0.372)$ \\
\hline Rmsd bond length $(\AA)$ & 0.015 & 0.020 & 0.011 \\
\hline Rmsd bond angle $\left(^{\circ}\right)$ & 2.2 & 2.3 & 2.0 \\
\hline \multicolumn{4}{|l|}{ Average B factor $\left(\AA^{2}\right)$} \\
\hline Protein & 33.1 & 26.5 & 51.4 \\
\hline $\mathrm{C}_{14} \mathrm{PC}$ & 60.9 & 68.6 & 102.1 \\
\hline Water & 47.5 & 40.1 & 60.0 \\
\hline Ion & 70.8 & 73.8 & 120.0 \\
\hline \multicolumn{4}{|l|}{ Ramachandran plot } \\
\hline Favored (\%) & 96.9 & 96.0 & 94.0 \\
\hline Allowed (\%) & 3.1 & 4.0 & 6.0 \\
\hline Disallowed (\%) & 0 & 0 & 0 \\
\hline
\end{tabular}

*Data for highest-resolution shell are given in parentheses. 
A

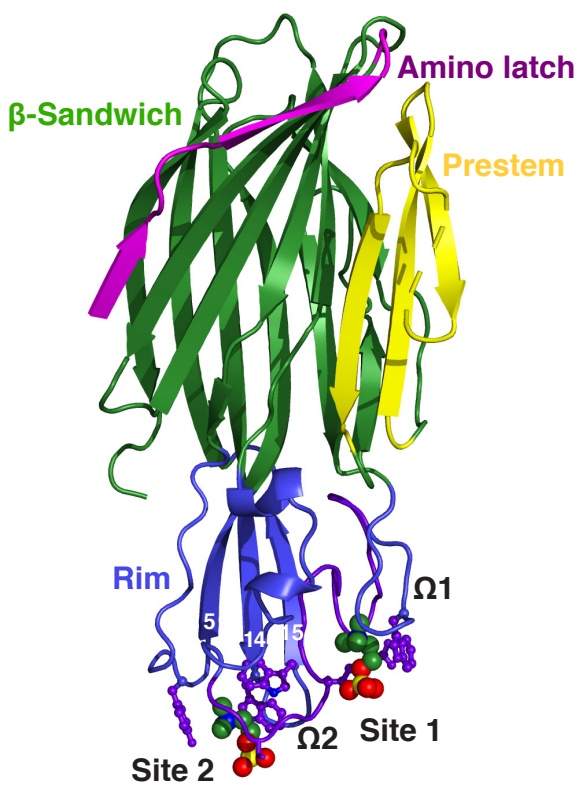

B

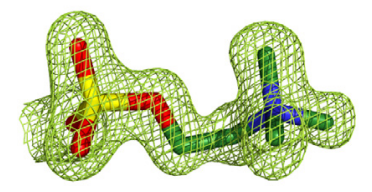

Site 1

C

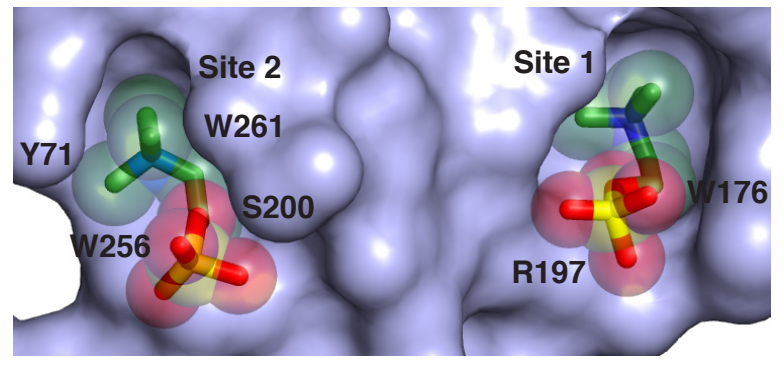

D

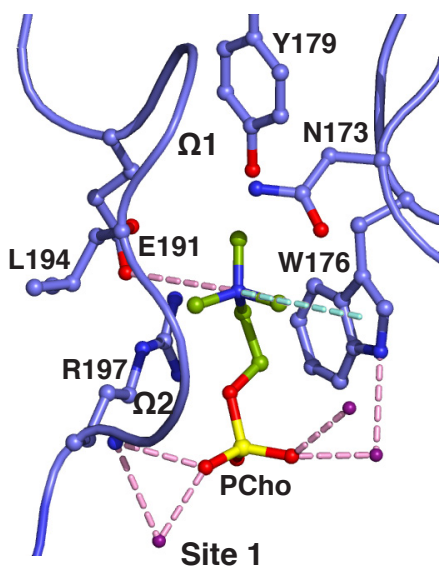

E

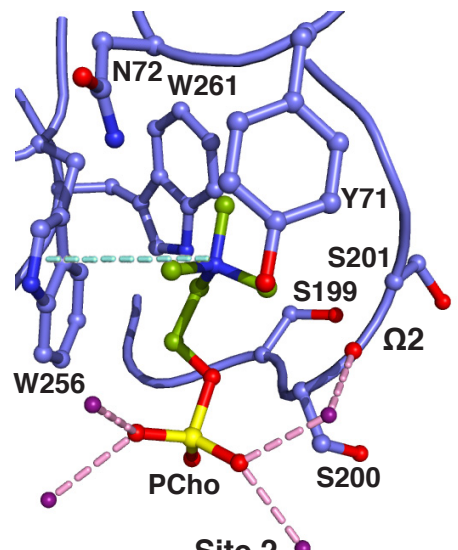

Site 2

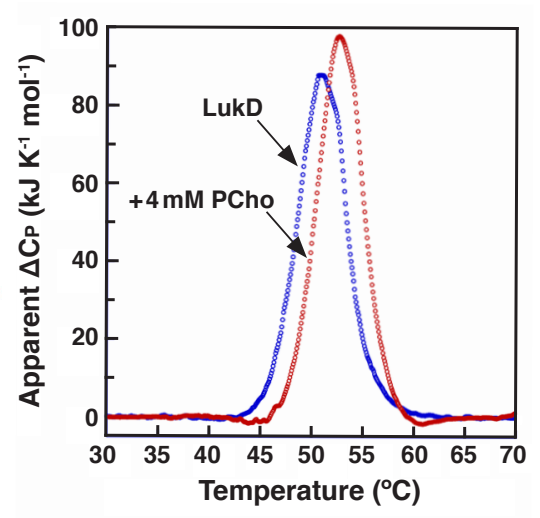

\section{Liu et al. Figure 1}


A

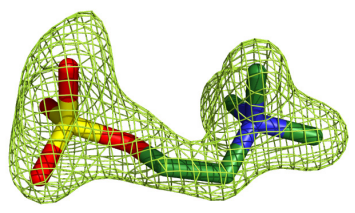

Site 1

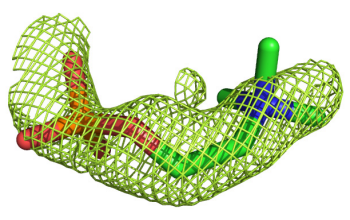

Site 2
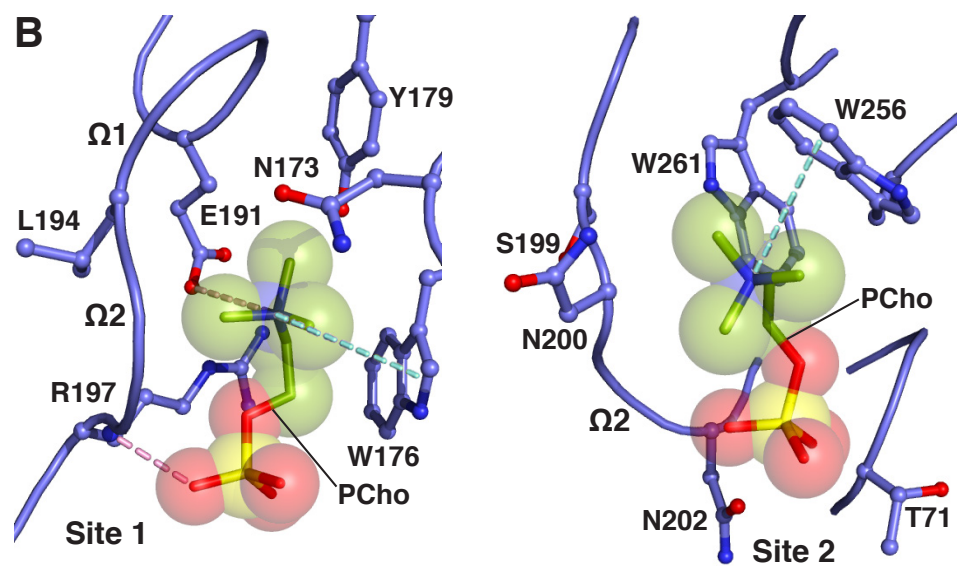

C

$$
71 \quad 75170
$$$$
180191
$$

202255

264109

117137 145

LukF-PV TISSQ KIMNNGWGPYG EMFLGSRQSNL..N FWNQL.......HWIGN QVQQTVGYS SFSETINYK

HIgB YDFSK KIMNNGWGPYG ELFLAGRQSSA..Y RWNGF....... YWAGA QVQNTLGYT AFSETINYK

LUKB YWNST LINNMGHDHTR EIFSLTRNGNL..W DWNRHGFWG..YWSGE EVKYTYGYK NYSETISYQ

LUKD YNYSQ KIMNNGWGPYG ELFLGGRQSSS..N QWNRL......HWVGN QVQQTLGYS SFSETINYK

a-Toxin ANKSG NMVNQNWGPYD QLFMKTRNGS..MK HWTSTN......WKGT EYMSTLTYG SIGHTLKYV

LUKS-PV DHIKA SFITSLGKMSG NLFVGYKPYSQ..N TRRTTHYGNSYLEGSR NVSQTLGYN NYSKTISYN HIgA PYIKR SFVTPNGQVSA YLFAQDPTGP...A YVT.RHR....LAVDR DVSQKLGYN NYSKTISYN

$\mathrm{HIgC}$

LukA NHVKA SFATESGQKSA DLFVGYKPHSK..D IKRSTHYGNSYLDGHR NVSQTLGYN NYSKSISYT KNSNW DLKYGGEVKNR LLFYRNTRIATVEN RPG.IHY....APPIL KVDSTFSYS SYSKTISYN

LukE ELTKR EFVTPDGKKSA YLFVQSPNGPTG.S TLFPRTG....IYAER DVGQTLGYN NYSKTISYT

\section{Liu et al. Figure 2}


A

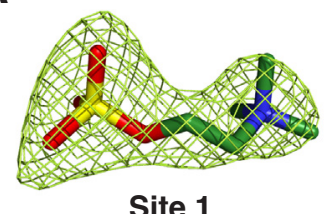

Site 1

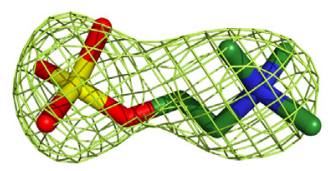

Site 2

C

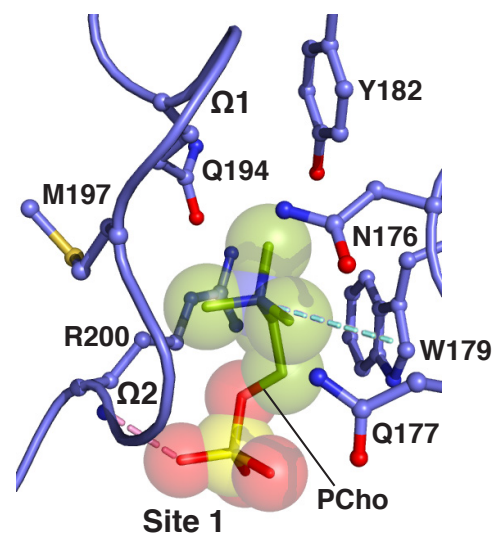

B
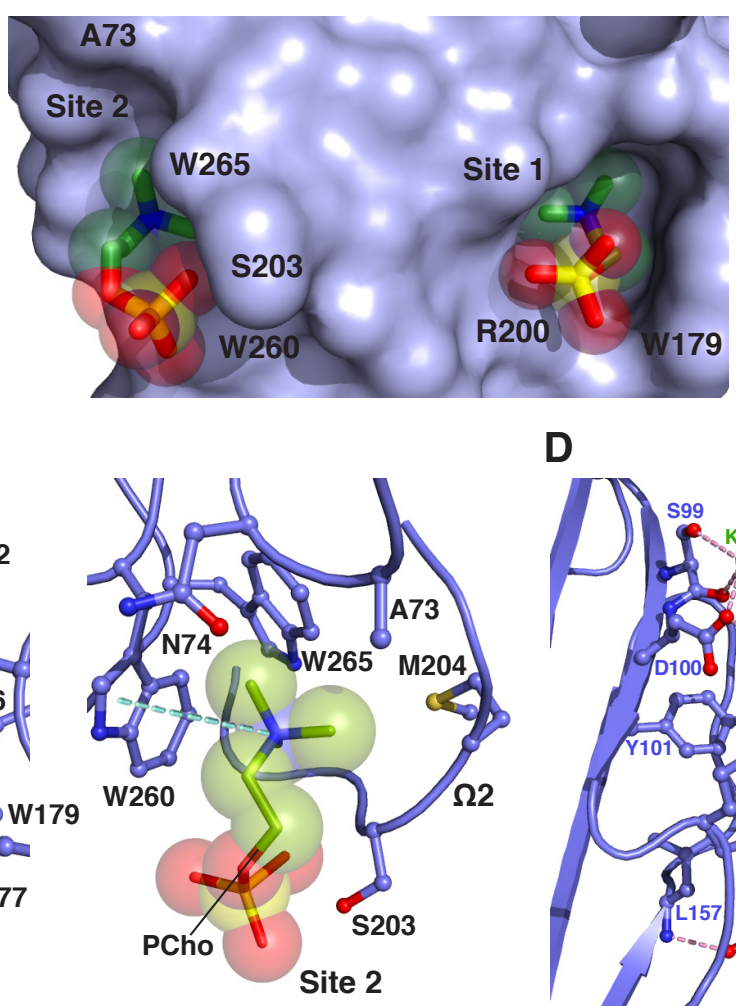

D

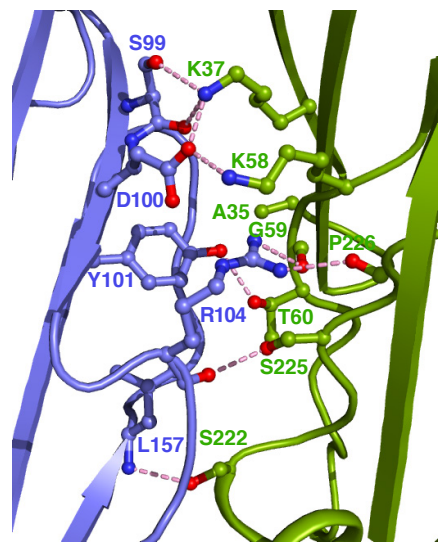

\section{Liu et al. Figure 3}


A

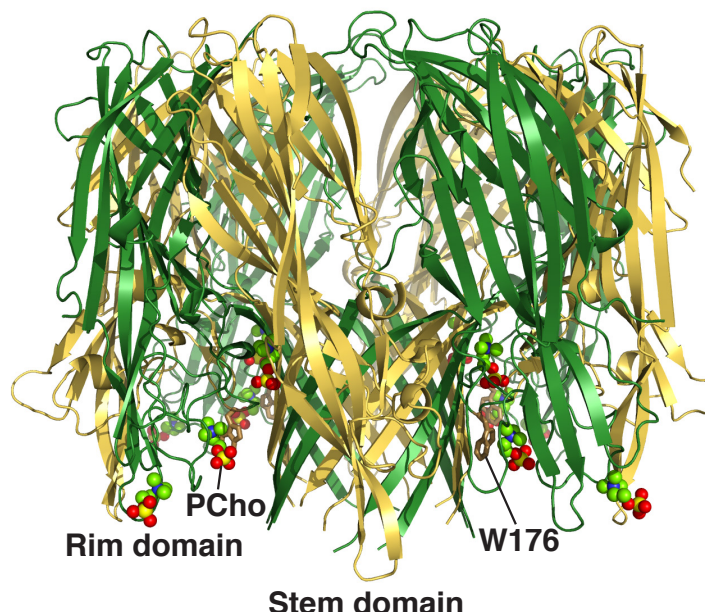

Stem domain
B

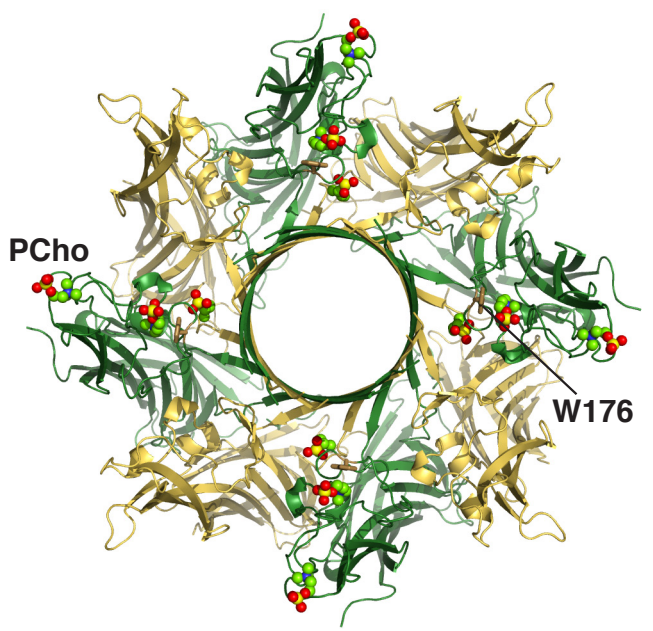

C
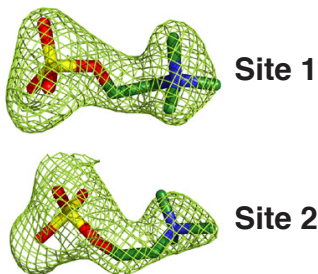

Site 2

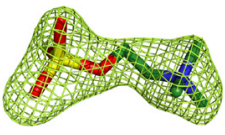

Site 3
D

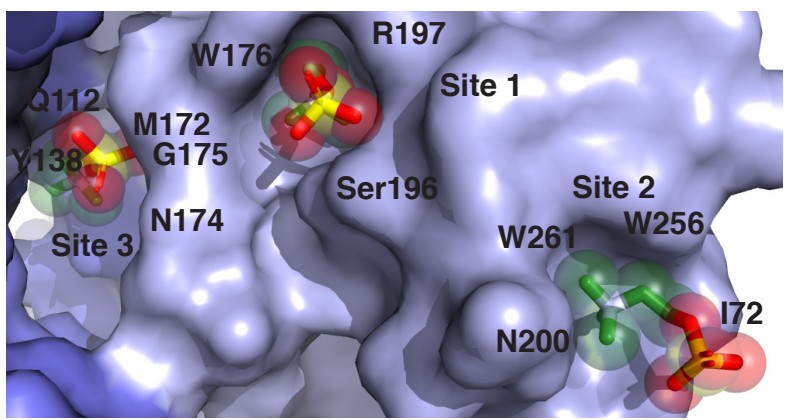

$\mathbf{E}$

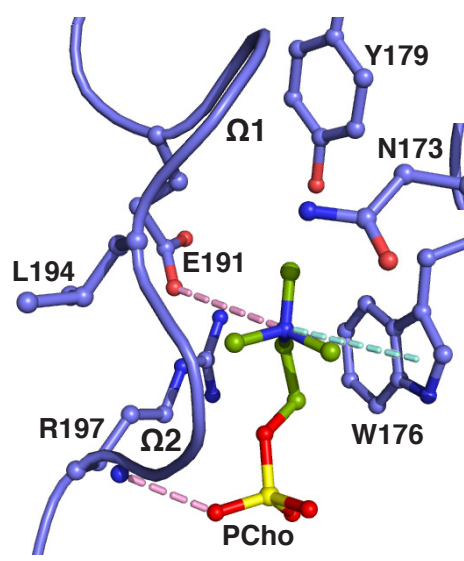

Site 1

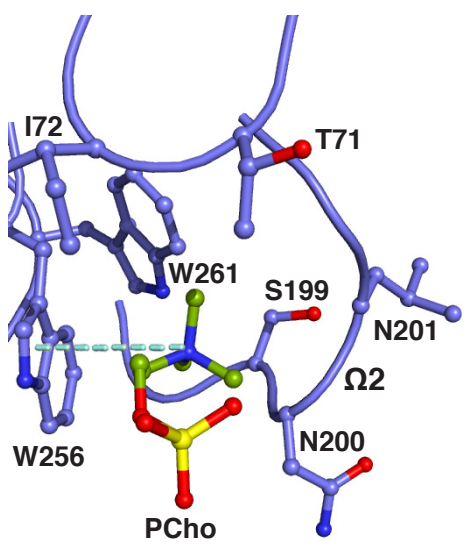

Site 2

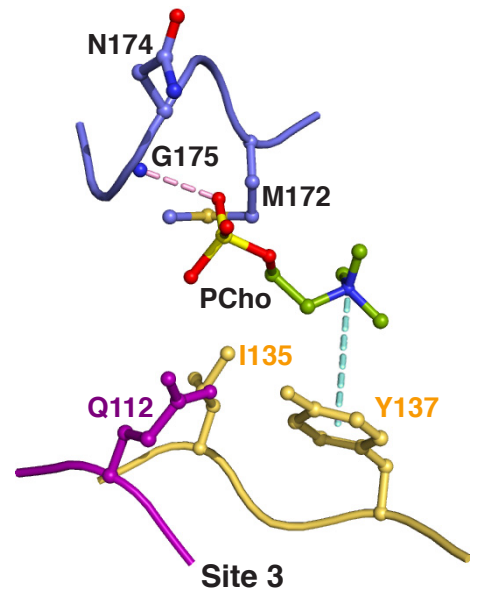

\section{Liu et al. Figure 4}




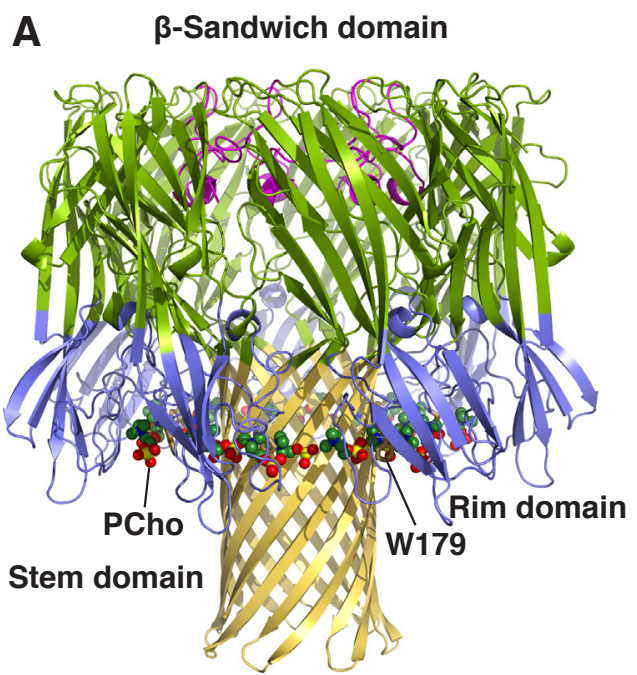

C

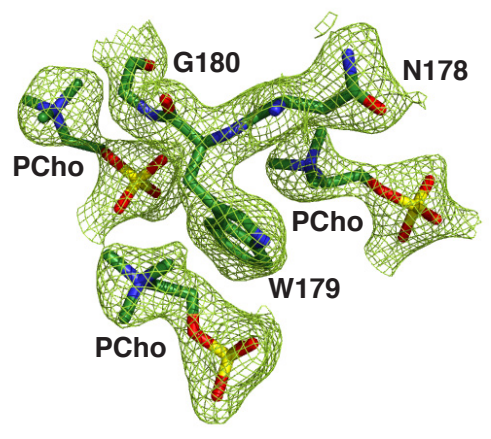

E

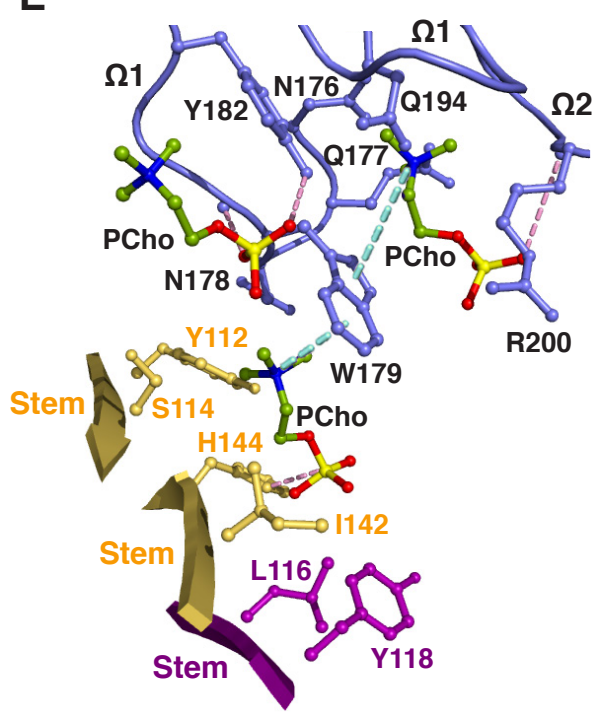

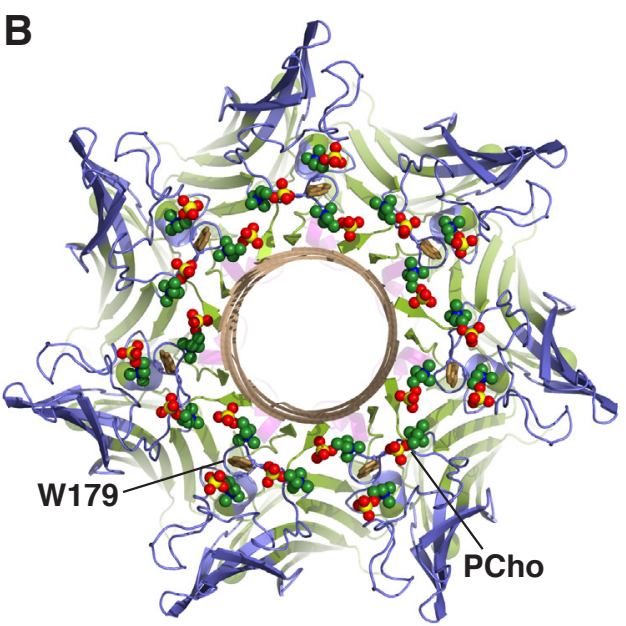

D

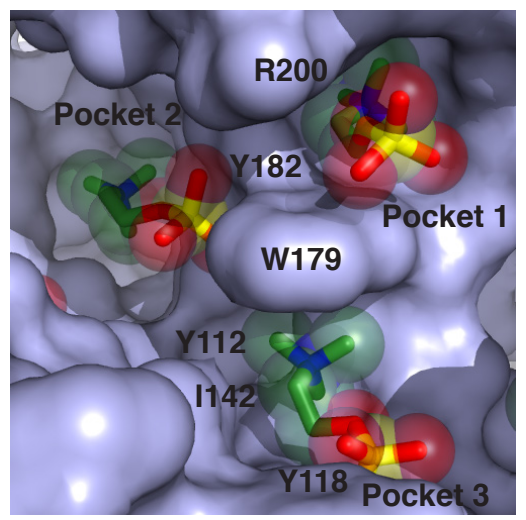

$\mathbf{F}$

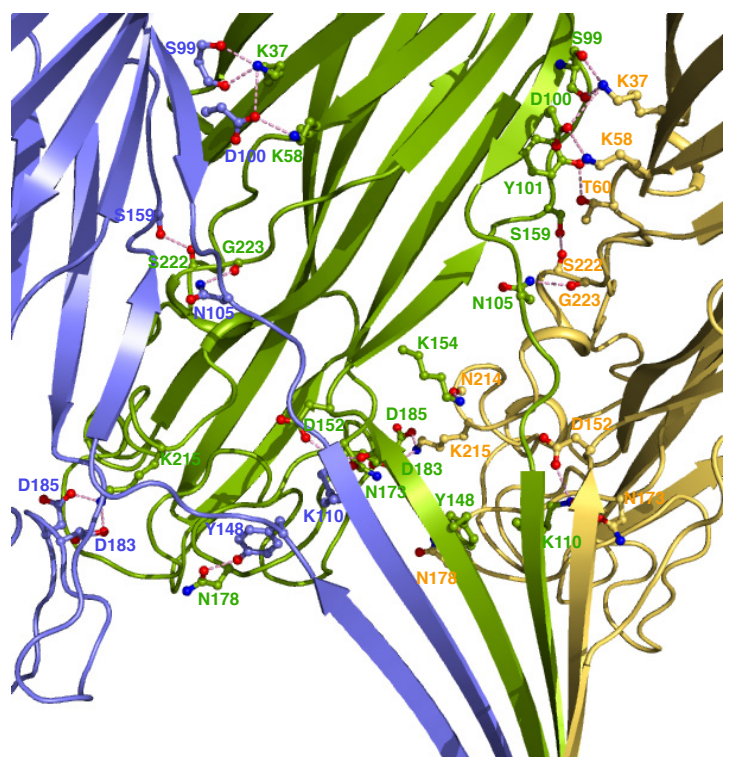

\section{Liu et al. Figure 5}


A

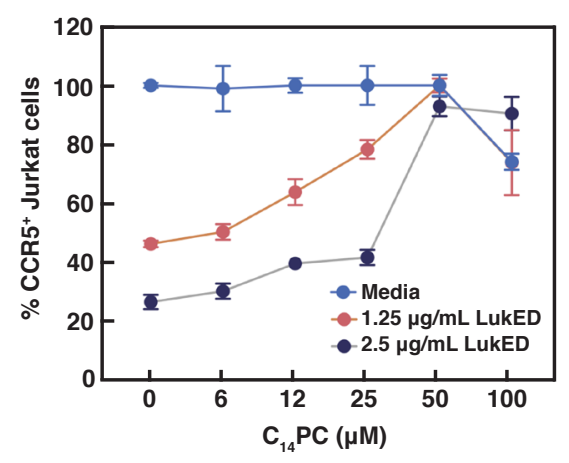

D

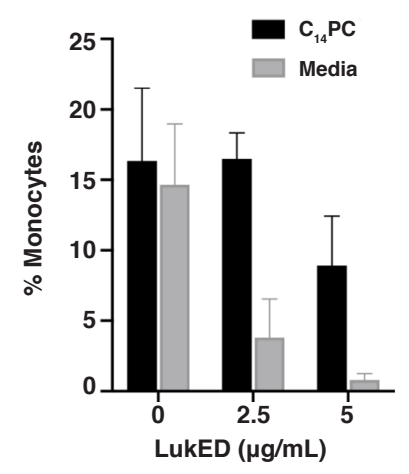

E

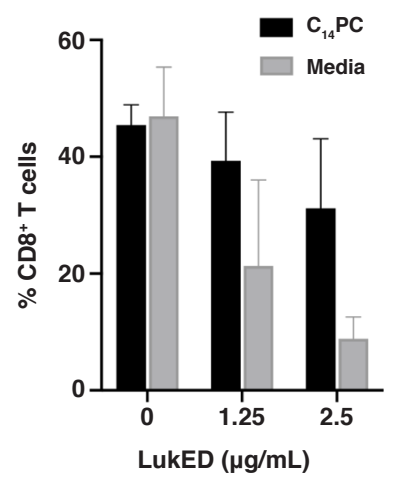

B

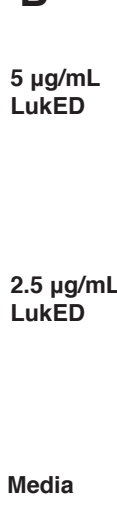

F
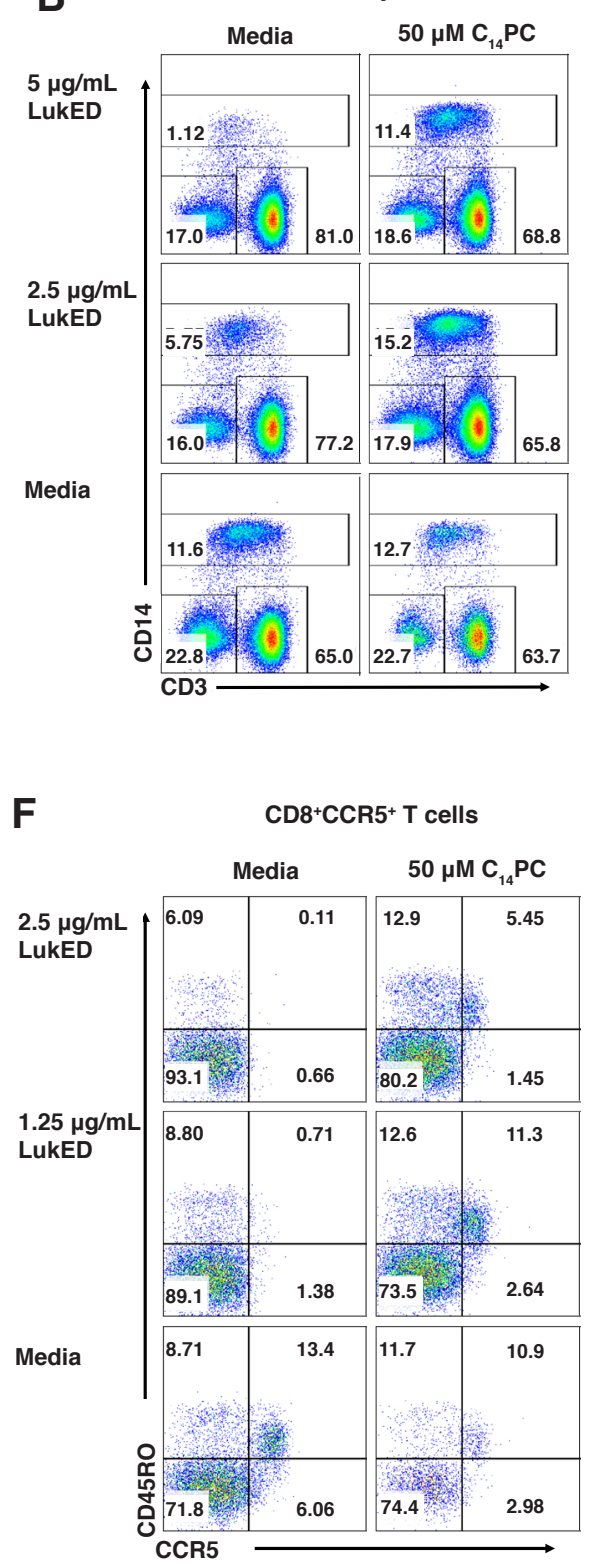

C

G

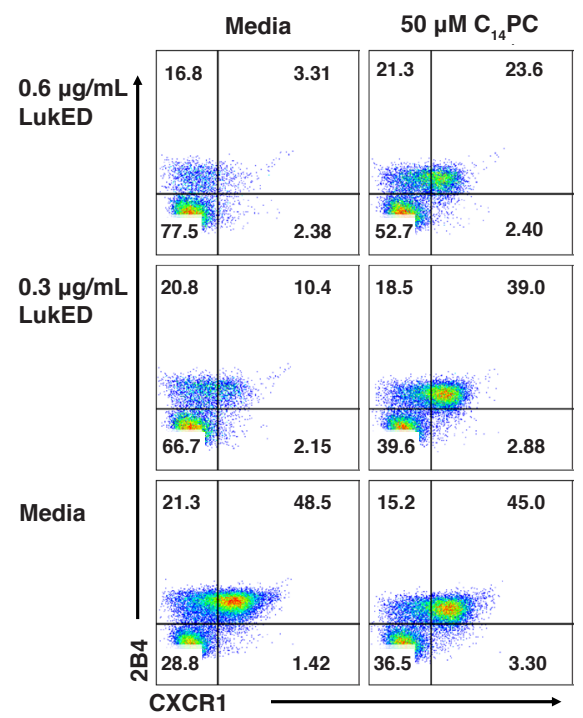

\section{Liu et al. Figure 6}


A

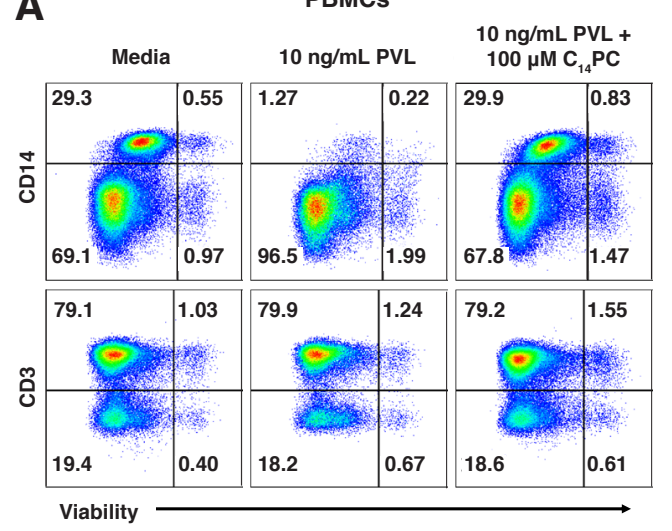

C

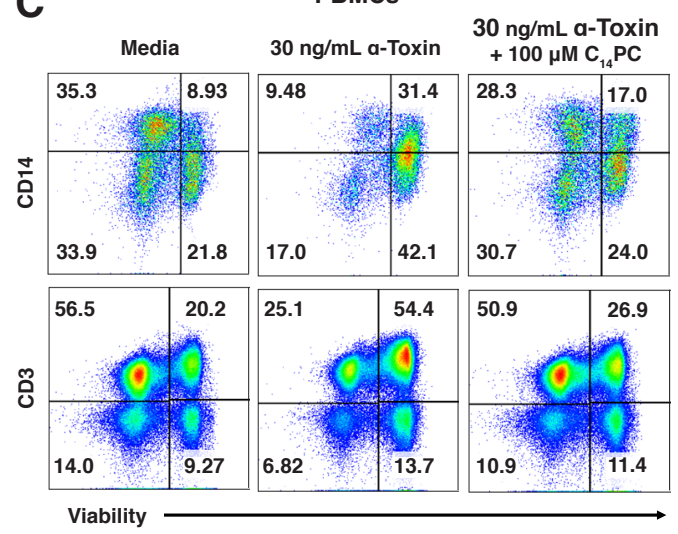

B

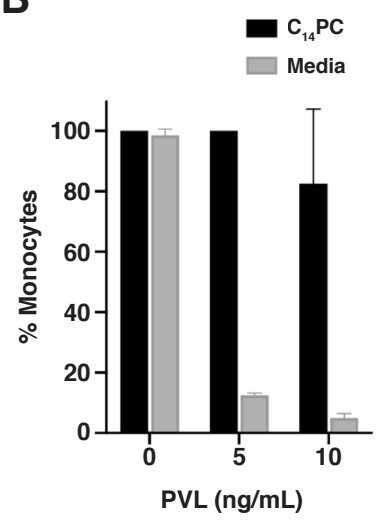

D

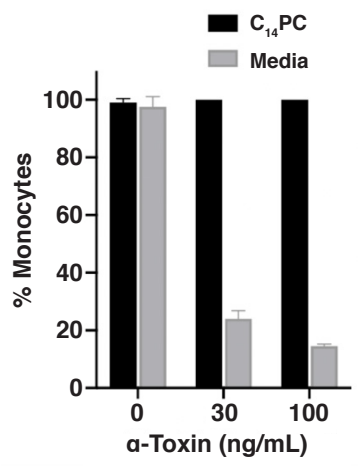

\section{Liu et al. Figure 7}

